\title{
Human Molecular Genetics
}

\section{Loss of Cln5 leads to altered Gad1 expression and deficits in interneuron development in mice}

\begin{tabular}{|c|c|}
\hline Journal: & Human Molecular Genetics \\
\hline Manuscript ID & HMG-2019-D-00066.R1 \\
\hline Manuscript Type: & 2 General Article - UK Office \\
\hline $\begin{array}{r}\text { Date Submitted by the } \\
\text { Author: }\end{array}$ & $n / a$ \\
\hline Complete List of Authors: & $\begin{array}{l}\text { Singh, Yajuvinder; University of Eastern Finland, A. I. Virtanen Institute } \\
\text { for Molecular Sciences } \\
\text { Leinonen, Henri; University of Eastern Finland, A. I. Virtanen Institute for } \\
\text { Molecular Sciences; University of California Irvine School of Medicine, } \\
\text { Department of Ophthalmology } \\
\text { Fazaludeen, Feroze; University of Eastern Finland, A. I. Virtanen Institute } \\
\text { for Molecular Sciences } \\
\text { Jaronen, Merja; University of Eastern Finland, A. I. Virtanen Institute for } \\
\text { Molecular Sciences } \\
\text { Guest, Debbie; Animal Health Trust, Animal Health Trust } \\
\text { Buckley, Noel; University of Oxford, Department of Psychiatry } \\
\text { Byts, Nadiya; University of Oulu, Oulu Centre for Cell Matrix Research, } \\
\text { Biocenter Oulu and Faculty of Biochemistry and Molecular Medicine } \\
\text { Oksa, Petra; University of Eastern Finland, A. I. Virtanen Institute for } \\
\text { Molecular Sciences } \\
\text { Jalkanen, Kari; University of Eastern Finland, A. I. Virtanen Institute for } \\
\text { Molecular Sciences } \\
\text { Iqbal, Imran; University of Eastern Finland, A. I. Virtanen Institute for } \\
\text { Molecular Sciences } \\
\text { Huuskonen, Mikko; University of Eastern Finland, A. I. Virtanen Institute } \\
\text { for Molecular Sciences } \\
\text { Savchenko, Ekaterina; University of Eastern Finland, A. I. Virtanen } \\
\text { Institute for Molecular Sciences } \\
\text { Keksa-Goldsteine, Velta; University of Eastern Finland, A. I. Virtanen } \\
\text { Institute for Molecular Sciences } \\
\text { Chew, Sweelin; University of Eastern Finland, A. I. Virtanen Institute for } \\
\text { Molecular Sciences } \\
\text { Myllyharju, Johanna; University of Oulu, Oulu Centre for Cell Matrix } \\
\text { Research, Biocenter Oulu and Faculty of Biochemistry and Molecular } \\
\text { Medicine } \\
\text { Tanila, Heikki; University of Eastern Finland, A. I. Virtanen Institute for } \\
\text { Molecular Sciences } \\
\text { Ooi, Lezanne; University of Wollongong, Illawarra Health and Medical } \\
\text { Research Institute, School of Biological Sciences } \\
\text { Koistinaho, Jari; University of Eastern Finland, A. I. Virtanen Institute for } \\
\text { Molecular Sciences } \\
\text { Kanninen, Katja; University of Eastern Finland, A. I. Virtanen Institute } \\
\text { for Molecular Sciences } \\
\text { Malm, Tarja; University of Eastern Finland, A. I. Virtanen Institute for }\end{array}$ \\
\hline
\end{tabular}




\begin{tabular}{|l|l|}
\hline & Molecular Sciences \\
\hline Key Words: & $\begin{array}{l}\text { Embryonic development, Neurodegenerative disease, Neuronal Ceroid } \\
\text { Lipofuscinosis, Lysosomal storage disease, Pediatrics }\end{array}$ \\
\hline
\end{tabular}




\section{REVIEWERS' COMMENTS}

We have carried out a large number of new experiments to answer the reviewer comments, as outlined below. A new author, Dr Sweelin Chew, has therefore been added to the author list.

\section{Reviewer: 1}

How the lack of a lysosomal protein affects development and more specifically interneuron development remains open. It remains unclear, how CLN5 regulates the levels of REST.

This is a good point. Although the direct mechanisms how CLN5 regulates the levels of REST is beyond the scope of this study, there are a number of studies providing evidence that conditions related to cell stress increase the levels of REST $(1,2)$. These include oxidative stress (1), inflammation (3), ischaemia (4) and epileptic seizure (5). Importantly, oxidative stress and inflammation are implicated in several NCL forms (6-8) and a well-established feature of the pathology in the CLN5-KO mice used in this study. The increase of REST is believed to protect neurons from oxidative stress and consequently, REST downregulation has been shown to lead to neurodegeneration (1). Loss of Cln5 alters proliferation, differentiation and apoptotic cell death. We propose that the loss of the lysosomal protein Cln5, increases inflammation and oxidative stress, leading to an upregulation of REST and a consequent downregulation of genes required for GABAergic differentiation, including Gad67 and Ptfla. Importantly, we show for the first time that this may occur through direct interaction of REST with Gad67. Ptfla is expressed in precursors to GABAergic neurons and is required for both early and late interneuron development (9). Consequently, misspecification of neurons in Ptfla-null mice results in a complete loss of inhibitory GABAergic neurons. This pathway is mediated by Lhx5 and Pax2, both of which were also identified as REST target genes (manuscript table S1). Together these findings suggest that REST regulates a panel of genes necessary for interneuron development. We have now amended the discussion accordingly.

How the findings are related to the human disease is also unclear. Is the contribution of the developmental delay indeed an important component of the human disease? This question is relevant in regard to possible future therapeutic approaches and the time point to start such therapies, like gene therapy.

As the reviewer is aware, the NCLs affect primarily children, and thus it is very difficult to access material for study from the patients. In an attempt to address whether the changes we observed in the CLN5-KO mouse model are represented in humans, we have obtained fibroblasts from healthy controls and two children suffering from Cln 5 disease. These precious samples were probed for REST expression by qPCR, but no differences were observed (data shown below). This did not come as a surprise given that fibroblasts are very different from CNS cells, and thus cannot be directly compared to our observations in CLN5-KO mice. We do however think, based on our data, that a developmental delay is a component of CLN5 deficiency and feel that this initial finding is very important, and deserves to be considered in future studies of also other NCL forms. Further studies to fully delineate the contribution of developmental delay to this disease are beyond the scope of the current study, but clearly required. 


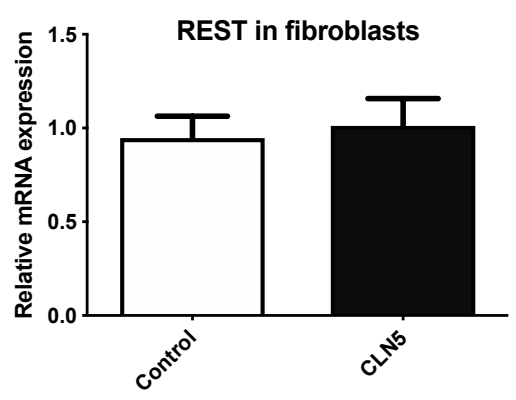

The typical hallmark of NCLs is the accumulation of neuronal ceroid lipofuscin, and typically hydrophobic proteins proteins like saposins and subunit $\mathrm{C}$ of the mitochondrial ATPase (SCMAS) accumulate in lysosomes. Lysosome-size is strikingly increased. The authors should include experiments in which they show, if CLN5 KO mice, maybe in neuronal subpopulations (e.g. PV-positive), show already signs of lysosomal storage, e.g. by LAMPimmunohistochemistry, histology for autofluorescence, SCMAS-immunohistochemistry or even electron microscopy at early developmental stages, and also in comparison to adult mice: are PV-positive cells more heavily affected compared to others?

As suggested by the reviewer, we have carried out a double immunohistochemical staining for the neuronal nuclear antigen Neu and parvalbumin (PV) in CLN5-KO mouse brain sections. While the embryonic mouse brains show no autofluorescence, coronal brain sections of adult CLN5-KO mice displayed autofluorescence for lipofuscin in PV-positive neurons in the cortex, hippocampus and in the thalamus. Conversely, little autofluorescence was detected in adult wildtype mice (example images shown below). These results indicate that the PV-positive subpopulation of cells shows some evidence of lysosomal storage in adult mice. The fact that both PV-positive cells and PV-negative neuronal cells appear to be equally affected suggests that autofluorescence is not specific only for the PV-positive neurons.
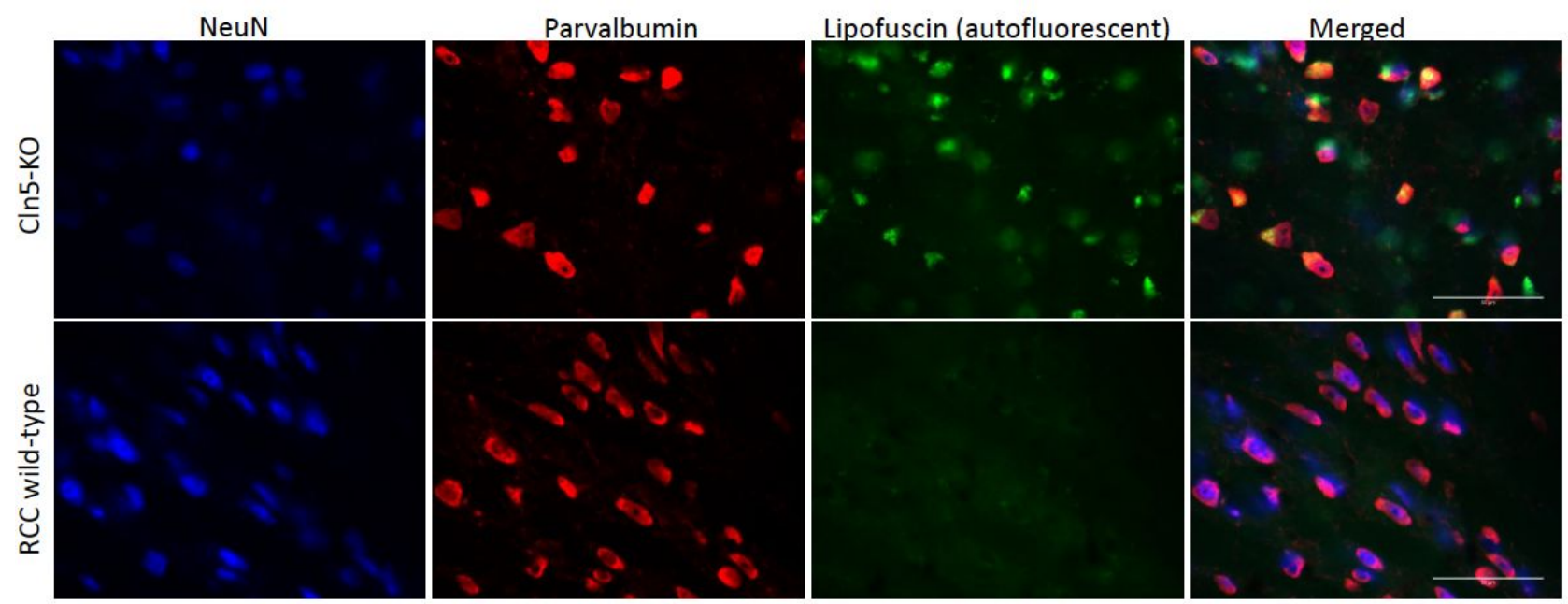

Thalamus, Scale bar 100 um. 


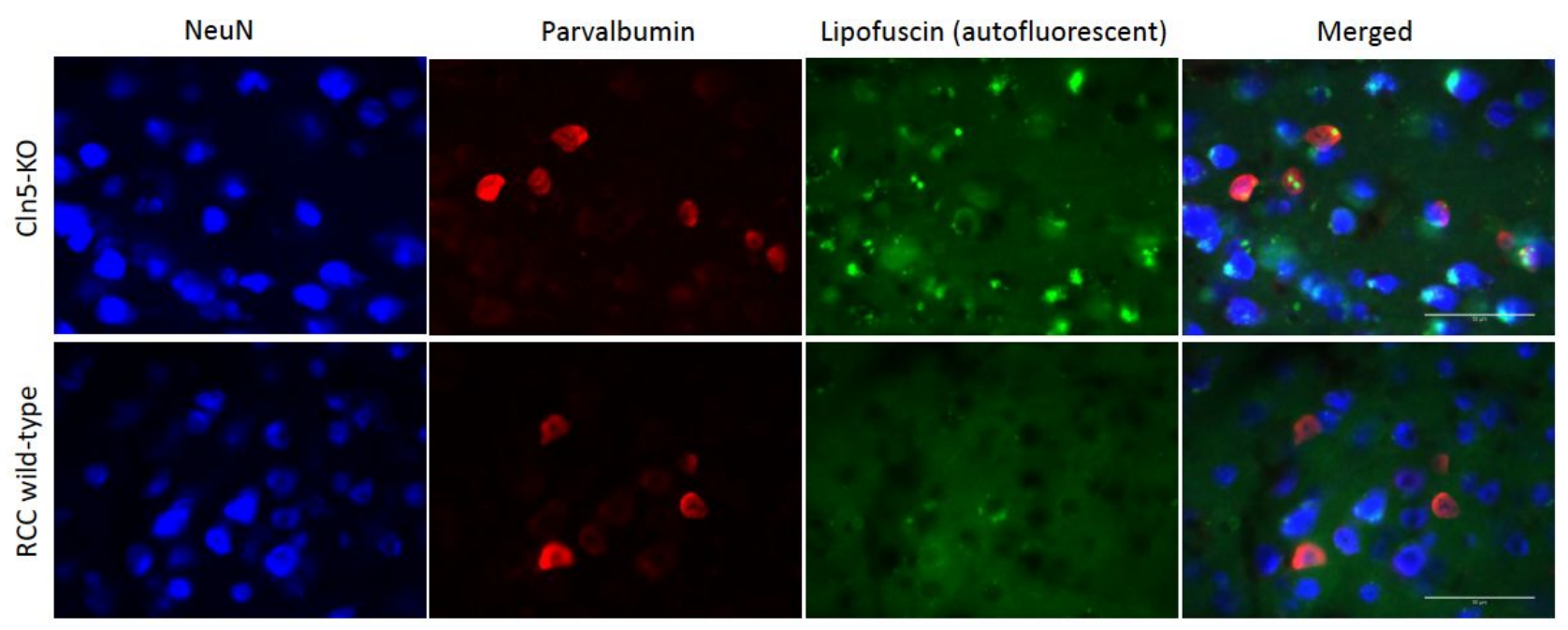

Cortex, Scale bar 50 um.

Previous papers suggested a major role of CLN5 in myelination. Could the changes observed in adult mice, including the behavioral data, related to altered myelination? This possibility should be at least discussed.

Indeed, earlier studies in the CLN5-KO mice have revealed a generalized early myelinisation defect, which did not progress between the ages of 1 and 3 months (10). In general, it is quite difficult to assess the contribution of hypomyelinization to behavior, since in all models there are additional neurodevelopmental changes or other pathology such as neuroinflammation in induced hypomyelinization models. In terms of the current study, it is possible that the demyelination contributes to the observed impairment in the Rotarod test, that draws on fast communication between the cerebellum and spinal cord via long myelinisated axons. This has now been discussed in the manuscript.

The authors mention a ChIP microarray experiment that led to the conclusion, that REST regulates GABAergic development. If possible, these data should be included in the supplement.

Selected highly enriched genes in ChIP microarrays in NS5 cells are now shown in Table 1. All the data has been added in the supplementary data section of the manuscript.

ChIP-qPCR from NS5-cells and hippocampal samples confirmed the regulation of Gag67 and Ptf1a by REST. The authors should include qPCR experiments (from hippocampal samples) to measure global expression changes of those genes in total RNA samples (not ChIP).

As suggested by the reviewer, we have now carried out $m R N A$ expression analyses in the hippocampi of 6-month old wildtype and CLN5-KO mice by qPCR. Global expression of Gad67 was not altered in the CLN5-KO hippocampi. This is now mentioned in the results section of the manuscript. The levels of Ptfla were too low for detection by qPCR (data not shown). 


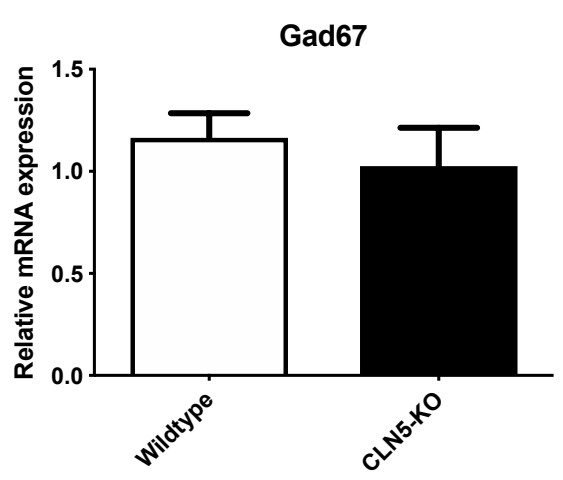

I'm wondering if, both in E14.5 animals and adult CLN5 KO animals, a redistribution of REST can be observed... antibodies for immunohistochemistry have been described (e.g. https://www.ncbi.nlm.nih.gov/pubmed/24670762) . This should be tested experimentally.

As suggested by the reviewer, we have carried out immunohistochemical stainings for REST in the CLN5-KO mice. Brains sections were co-labelled for REST and DAPI, a DNA counterstain. Ni-DAB development was used to reduce the effect of autofluorescence on image quality. Images acquired under 60x magnification with $2 x$ zoom reveal that the majority of REST appears to be located within the nuclei in the cortex as well as hippocampus of CLN5-KO mice. No visible difference in REST redistribution between wildtype and CLN5-KO was observed (images below). This suggests that REST re-distribution is not behind the observed effects. This has now also been mentioned in the manuscript.
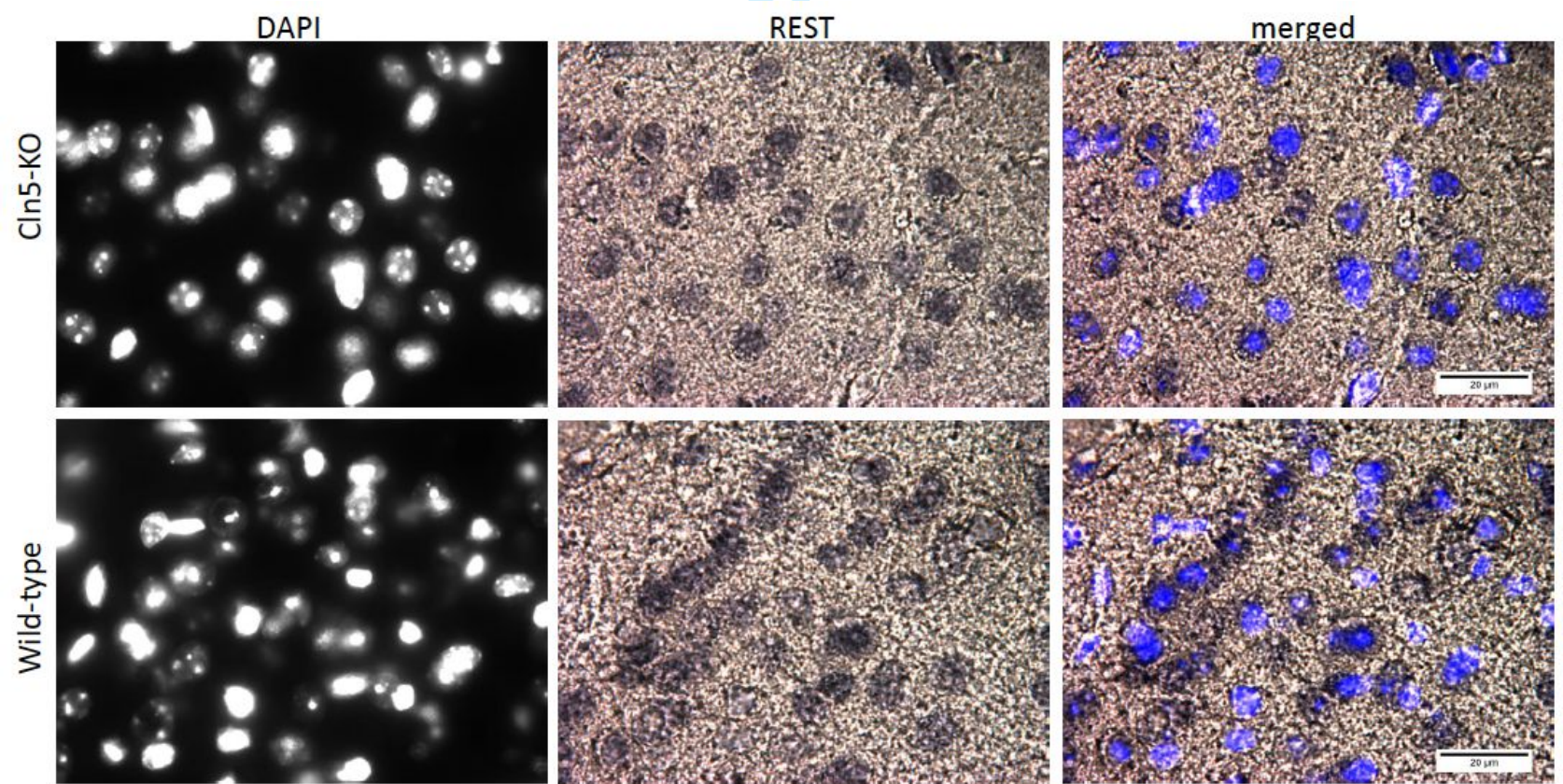

Cortex, scale bar 20 um. 

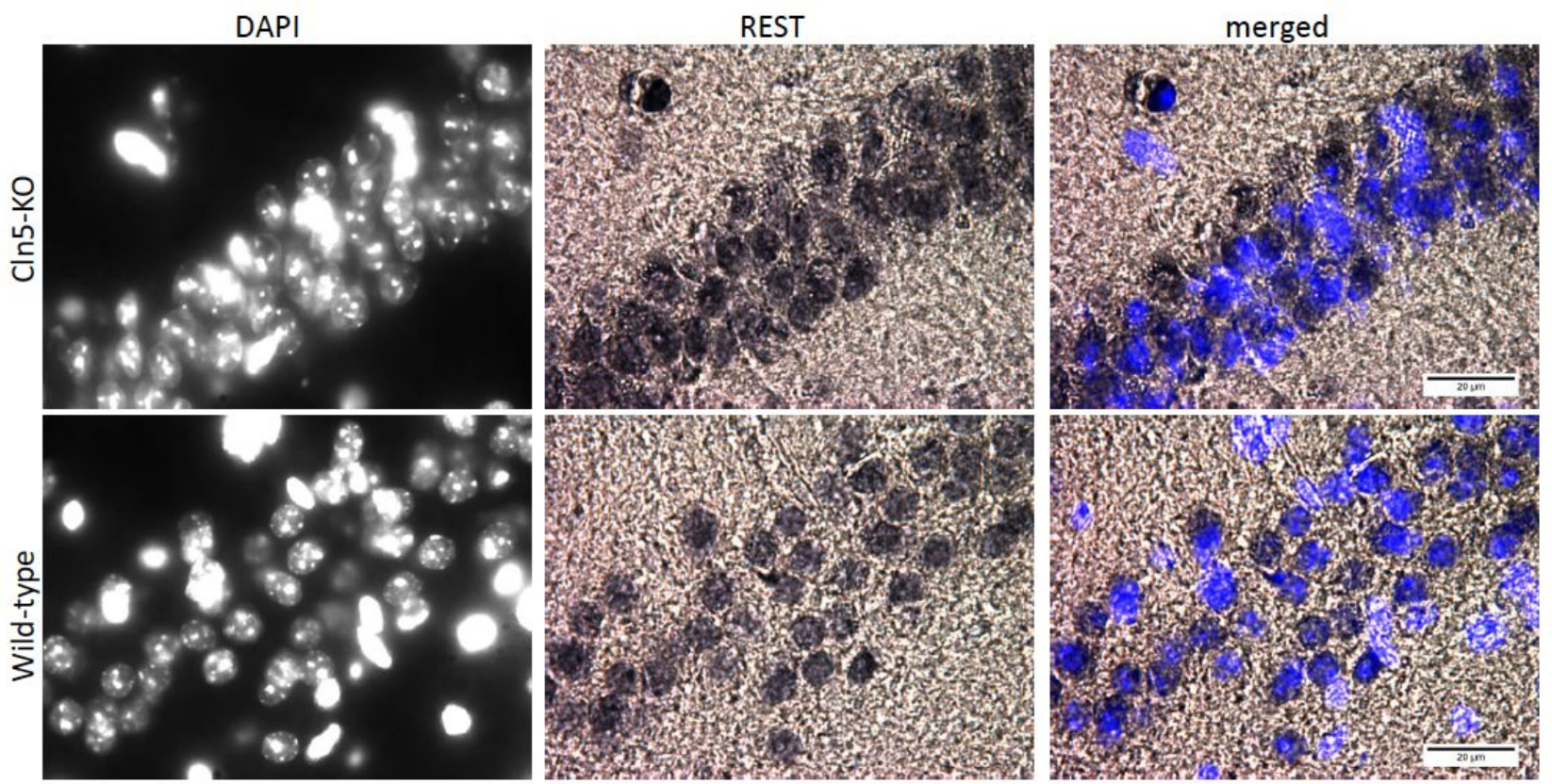

Hippocampus, scale bar $20 \mathrm{um}$.

Minor:

1.) Introduction (lane 19): It is meanwhile well accepted, that CLN5 is a soluble lysosomal glycoprotein (not "speculated").

The term 'speculated' has now been changed to "well accepted".

2.) The discussion should be shortened significantly.

As suggested by the reviewer, we have attempted to shorten the discussion section. However, several of the points raised by the reviewers have required lengthening the discussion by including more explanation, making it very difficult to reduce the overall length of this section.

\section{$\underline{\text { Reviewer: } 2}$}

The authors seem to make on finding (that in and of itself is interesting) but then they don't link that finding directly to the next step in their story. Instead these take a few steps forward in the logic so that key pieces of the story seems to be missing. In some cases this can resolved with more explanation of the data but in others it may require additional experiments to fill in the gaps.

As requested by all reviewers, we have now carried out numerous extra experiments to address these comments, fulfill gaps and to make the story more logical. For instance, the order of figures has been changed and one previous figure was split into two to make the links between steps stronger. We have also attempted to further explain the data in the updated manuscript. 
1) The authors state that there are 14 NCLs - although the numbers run 1-14 in the gene names, there is no CLN9 (so only 13 NCLs).

This has now been corrected in the introduction section.

2) The authors state that there are no changes in Nestin+ cells yet there is an increase in Pax6+ cells in the ventricular zone. Shouldn't all Nestin+ radial progenitors also be Pax6+? Therefore, its unclear how these numbers differ?

This is a good point and we thank the reviewer for bringing this up so that we can clarify the issue. Indeed, in the developing brain virtually all Pax6+ cells are also positive to nestin, as shown by Götz et al (1998, Neuron). However, the authors nicely show that there is a significant proportion of cells that are nestin positive but Pax6 negative. This pax6 negative but nestin positive population could overcome the observed difference in the extent of Pax6 positive and nestin positive cell populations. We have now modified the discussion part accordingly.

3) The authors mention that there are increased Pax6+ cells but decreased TuJ1+ cells during early corticogenesis. There could be many causes for this. Is the radial scaffold intact (the author have supplemental data that the Nestin+ numbers don't change but show no Nestin images to be able to determine if the scaffold itself is ok. Is the increase in Pax6+ cells because there are changes in the length/dynamics of the cell cycle -- ie., the cells are remaining as apical progenitors longer and not exiting the cell cycle. The authors use the Pax6+ increase to make a statement that proliferation of cells in the dorsal $\mathrm{VZ}$ is increased, but they don't actually directly look at this. The authors did Ph3 counts in the GE but could do the same counts in the dorsal ventricular zone to understand more about these Pax6+ cells and the proliferation in this compartment. Are the apical progenitors ever transitioning to become basal progenitors (are they moving away from the ventricular zone to SVZ or becoming Tbr2+ progenitors)?

This is an important point and indeed, an increase in the PAX-6 staining in the dorsal telencephalon can be a result of several factors such as changes in proliferation, scaffolding, cell death rate, changes in cell fate choice or any combination of these factors. As kindly suggested by the reviewer to exclude the possibility that increase in PAX-6 immunoreactivity in CLN5-KO embryos may have been due to abnormal $R G$ scaffolds, we examined $R G$ scaffolding with nestin staining at E14.5. However, for the majority of the sections the staining did not show any gross changes in $R G$ morphology (Figure S1A,B) suggesting that radial glial fibers are likely functionally normal in CLN5-KO embryos.

As suggested by the reviewers, we also analyzed the proliferative activity in the dorsal telencephalon with Ph3 counts. We observed a strong trend of an increase in the Ph3 counts in the dorsal telencephalon of E14.5 (intermediate and caudal sections) Fig. 2D-F). Thus, although we failed to provide double stainings for PAX6 and Ph3, our data suggests that PAX-6 increase was most likely due to an increase in the proliferative activity of the progenitor cells in the CLN5-KO embryos. We have now amended the discussion accordingly.

3) the authors perform TUNEL staining and counting in the cortical plate and GE. Although they don't say it directly, you are led to believe that the increases TUNEL in the cortical plate is correlated with the decreased interneurons being generated in the MGE. However the timepoints analyzed would match this story -- at E14.5 the migrating MGE derived 
interneurons would not have reached the dorsal cortex. And when they come in, they enter in a dorsal and ventral stream -- yet the TUNEL + cells are throughout the cortical wall. So what are the cells that are dying? In the first set of figures, TuJ1 neurons are decreased at E14.5 but catch up by birth -- so how do you have decreased neurons at the peak of corticogenesis, increased cell death but things normalize but birth?

The migration of interneurons form the ganglionic eminences (GEs) towards the dorsal pallium can roughly be divided into three waves (Reviewed by Marin et al. 2001). Early wave of migration begins around E11.5 where interneurons originating from medial ganglionic eminence (MGE) and anterior entopeduncular area (AEP) follow a superficial route to the developing striatum and invade marginal zone (MZ) and subplate (SP) in the cortex. Around E12.5-E14.5, when the MGE is the principal source of interneurons, they migrate tangentially into the cortex. These MGE derived interneurons either follow a deep or superficial migratory route and populate the sub ventricular zone (SVZ)/lower intermediate zone (IZ) and SP from where they eventually move on to the cortical plate. It is around E14.5-E1.6 that the late stage of interneuron migration occurs from both lateral ganglionic eminence (LGE) and MGE. As discussed above, although tangential migration is not fully complete by E14.5 but the cortex wall may well have a small number of interneuronal populations by this time point (mainly located in SVZ/IZ) therefore, the possibility of no involvement of interneuronal apoptosis in the cortex cannot be ruled out totally at E14.5.Developing brain has a high rate of apoptosis that involves cells from both the proliferative and post mitotic neuronal compartments (Burek et al. 1999; Rabinowicz et al.199; Rakic et al. 2001). Our studies indicate that at E14.5 Cln5-KO embryos have an abnormal rate of cell death when compared to the WT embryos, which can be seen throughout the entire telencephalic wall in the dorsal pallidum. Therefore, it is likely that in Cln5-KO embryos there is a high rate of apoptosis both in the precursor populations and in the post mitotic neurons. In support of the latter, we see that Tuj-1 positive staining is already decreased in the Cln5-KO mice, suggesting that neuronal apoptosis could be an important factor behind the loss of these neurons.

To add further, the increased TUNEL staining in the dorsal pallium wall likely represents both the neuronal progenitor cells and their neuronal populations. Nonetheless, involvement of some interneurons that have already populated the developing cortex by E14.5 cannot be ruled out. One of the aims of the current study was to explore the hypothesis that neurodegenerative diseases may have their origins during the in utero period (Barker et al. 2002; Barker et al. 2004; Lahti et al. 2010; Lahiri et al. 2009; Marques et al. 2013. It is hypothetized that many in utero developmental insults remain latent which can manifest later into an overt disease at some time point during the postnatal period or adulthood. A number of studies show that an initial insult during early development may result in postnatal brain anomalies (Buka and Fan, 1999; Jaaro-Peled et al. 2009; Silva et al. 2012). In an interesting study by Niwa et al. (2010), a transient knockdown of DISC1 during pre-/peri-natal stages, in a lineage of pyramidal neurons from prefrontal cortex, led to selective abnormalities in postnatal mesocortical dopaminergic maturation and behavioral abnormalities associated with disturbed cortical neurocircuitry after puberty. This study shows and example of early development deficits that affect postnatal brain function and cause behavioral phenotype in adulthood.

As a summary, the primary aim of this study was to draw the reader's attention towards the hypothesis that NCLs might have a crucial neurodevelopmental component since NCL associated genes, such as Cln5, show a high expression during the embryonic brain development. It was somewhat beyond the scope of the current study to link these early developmental changes to the brain pathology in adult Cln5 $5^{-/}$mice. Instead, we did a few simple experiments to show that the neurological phenotype in $\mathrm{Cln}^{-/-}$mice does not seem to aggravate with age, but rather seem to be acquired congenitally. 
4) When the authors do interneuron counts, they only look at one class of interneurons - parvalbumin + . However, numerous papers by Cooper et al have shown changes in several different classes of GABAergic interneurons in different forms of Batten disease. Are the authors missing changes in the cortex because of the limited examination.

We agree that many different classes of interneurons are affected in CLN disease and as such we also tried to look for other GABAergic neurons in the cortex. The caudal ganglionic eminence (CGE) gives rise to about 30\% of interneuronal populations (12) and the major subgroup of calretininexpressing (CR) interneurons originates mainly from the CGE (13). Since the CGE also showed anomalies in our experiments, we decided to analyze $C R$ immunoreactivity in the adult brain. However, we did not find differences in adult CLN5-KO cortex (Image below).
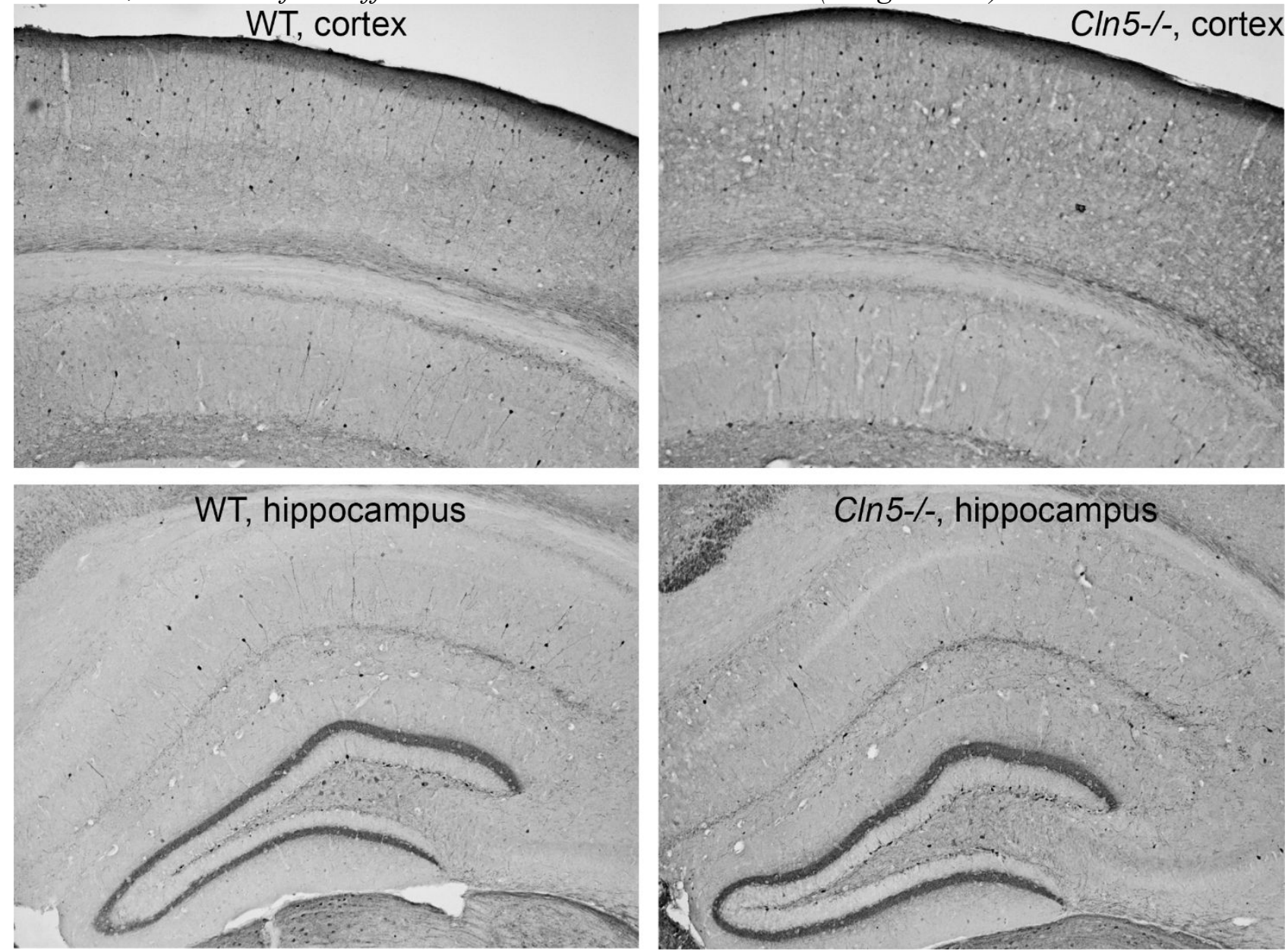

Calretinin immunohistochemistry.

5) For much of the histopathology, it is unclear what regions of the cortex the cell counts are being performed in. For instance, loss of GABAergic neurons in other forms of Batten disease has been shown to be associated with limited/distinct functional regions. Again are the authors missing differences because they are not restricting their analysis to particular regions.

This is again important comment and well taken by the authors. We indeed carried out analysis of parvalbumin positive cells in a number of different brain areas in the adult brains, including cortex, hippocampus and cerebellum. However, the only significant alterations were found in the CAI and hilus area of hippocampi. 
With regard to the embryos, we have added a supplementary figure S2 that shows the representative areas of interest where immunoreactivities were calculated in the WT and Cln5-KO embryonic brain sections. In the dorsal telencephalon (dT) the circles show the areas where immunoreactivities were analyzed in 200-400 $\mu \mathrm{m}$ wide windows spanning across the entire telencephalic wall. In the ventral telencephalon $(v T)$ the circles show the ganglionic eminences (GEs). The immunoreactivities in the GEs were mainly analyzed in lateral ganglionic eminences (LGE; upper circle in Intermediate section image), medial ganglionic eminences (MGE; lower circle in Intermediate section image) and caudal ganglionic eminence (circle in Caudal section image) in form of circles covering approximately $85000 \mathrm{\mu m}^{2}$ area. For IHC analysis, 2-3 anatomically matched sections from the rostral-caudal axis of WT and Cln5-KO embryos were taken. Wherever applicable different layers in the dorsal pallium were identified according to Bayer at al. 1991, based on cell morphology and density identified with a $20 X$ magnification. Mid dorsal pallium region of the embryo brain sections (dT) was visualized using 10x magnification and immunoreactivity per unit area was quantified in the different identified layers or entire telencephalic wall using a 200-400 $\mu$ m wide window with Image-Pro plus 6.0.

6) For the deficits in neurite outgrowth, does this correlate with any long term consequences in the mice -- ie., inability to form long distance fiber tracts $O R$ are there instance of white matter/DTI imaging deficits in human patients that would result from decreased neuritogenesis?

The neurite outgrowth assay was carried out in vitro in cultured cells. Therefore, a direct correlation to long-term consequences in vivo is difficult to make, and even more so, in patients. However, our in vitro data on neurite outgrowth provides important mechanistic information that fits with the in vivo findings of the study.

7) to extend the loss of interneurons to some behavioral deficits, the authors perform a number of behavioral assays. However, how do the auditory measures and rotatod assays performed correlate with loss of interneurons in the hippocampus? Wouldn't a learning and memory assay have been more suitable to correlate with hippocampal defects? Is there a direct circuit from the hippocampus that is involved in these measures?

Auditory evoked potentials (AEPs) as measured with the midline screw electrodes in rodents are sensitive to auditory gating in the hippocampus. Impaired auditory gating has been considered a measure of interneuron function in the hippocampus $(14,15)$ We have also observed overall increased AEPs in mice with defective perisomatic nets by interneurons (mainly PV) in cortex and hippocampus (16). The reviewer is right that part of our electrophysiologal recordings (cortical EEG) and Rotarod test do not have a direct correlate with interneuron population in the hippocampus. Instead, our electrophysiology data provide evidence of cortical hyper excitability that does not aggravate between 2 and 6 months of age, and thus appears to be acquired congenitally. Decreased inhibitory drive due to defects in the development of cortical interneurons provides a likely explanation for this finding.

Our 9-month rotarod follow-up, started at 1-month of age, strongly suggests that the motor phenotype too is congenitally acquired, and does not significantly progress in Cln5-KO mice. As we did not provide a direct anatomical correlate for this performance defect, we kept the data merely as curiosity and present it as supplementary data. 
To assess spatial learning and memory CLN5-KO mice, we performed Morris swim task which showed a significant performance impairment. Unfortunately, however, we cannot draw a solid conclusion whether the performance defect was caused by memory defect or visual impairment. The Cln5-KO mice display a robust retinal degeneration that affect rod-mediated vision from early life, and cone-mediated vision from approximately 5 months of age onwards (11).

8) There are number of acronyms in the paper that are never defined -- unless the reader is a neuroscientist, they may never know what these mean (EEG, PSD, AEP, RGC)

Abbreviations are now listed in the manuscript.

\section{9) There are several images that lack scale bars.}

Scale bars have now been added.

10) Figure 2 legend and labels of figure don't match. TUNEL in legend is A\&B but in the actual figure they are last.

We thank the reviewer for being observant. This mistake has been now corrected in Fig. 2 legend.

\section{REFERENCES}

(1) Lu T, Aron L, Zullo J, Pan Y, Kim H, Chen Y, Yang TH, Kim HM, Drake D, Liu XS, Bennett DA, Colaiácovo MP, Yankner BA. REST and stress resistance in ageing and Alzheimer's disease. Nature. 2014 Mar 27;507(7493):448-54. doi: 10.1038/nature13163.

(2) Ooi L, Wood IC. Chromatin crosstalk in development and disease: lessons from REST. Nat Rev Genet. 2007 Jul;8(7):544-54.

(3) Brennan GP, Dey D, Chen Y, Patterson KP, Magnetta EJ, Hall AM, Dube CM, Mei YT, Baram TZ. Dual and Opposing Roles of MicroRNA-124 in Epilepsy Are Mediated through Inflammatory and NRSF-Dependent Gene Networks. Cell Rep. 2016 Mar 15;14(10):2402-12. doi: 10.1016/j.celrep.2016.02.042.

(4) Calderone A, Jover T, Noh KM, Tanaka H, Yokota H, Lin Y, Grooms SY, Regis R, Bennett MV, Zukin RS. Ischemic insults derepress the gene silencer REST in neurons destined to die. J Neurosci. 2003 Mar 15;23(6):2112-21. PubMed PMID: 12657670.

(5) Palm K, Belluardo N, Metsis M, Timmusk T. Neuronal expression of zinc finger transcription factor REST/NR SF/XBR gene. J Neurosci. 1998 Feb 15;18(4):1280-96.PubMed PMID: 9454838.

(6) Pivtoraiko VN, Stone SL, Roth KA, Shacka JJ. Oxidative stress and autophagy in the regulation of lysosome-dependent neuron death. Antioxid Redox Signal. 2009 Mar;11(3):481-96. doi: 10.1089/ARS.2008.2263.

(7) Wei H, Kim SJ, Zhang Z, Tsai PC, Wisniewski KE, Mukherjee AB. ER and oxidative stresses are common mediators of apoptosis in both neurodegenerative and non-neurodegenerative 
lysosomal storage disorders and are alleviated by chemical chaperones. Hum Mol Genet. 2008 Feb 15;17(4):469-77.

(8) Fiorenza MT, Moro E, Erickson RP. The pathogenesis of lysosomal storage disorders: beyond the engorgement of lysosomes to abnormal development and neuroinflammation. Hum Mol Genet. 2018 Aug 1;27(R2):R119-R129.

(9) Glasgow SM, Henke RM, Macdonald RJ, Wright CV, Johnson JE. Ptfla determines GABAergic over glutamatergic neuronal cell fate in the spinal cord dorsal horn.Development. 2005 Dec;132(24):5461-9.

(10) Schmiedt ML, Blom T, Blom T, Kopra O, Wong A, von Schantz-Fant C, Ikonen E,Kuronen M, Jauhiainen M, Cooper JD, Jalanko A. Cln5-deficiency in mice leads to microglial activation, defective myelination and changes in lipid metabolism.Neurobiol Dis. 2012 Apr;46(1):19-29. doi 10.1016/j.nbd.2011.12.009.

(11) Leinonen H, Keksa-Goldsteine V, Ragauskas S, Kohlmann P, Singh Y, Savchenko E, Puranen J, Malm T, Kalesnykas G, Koistinaho J, Tanila H, Kanninen KM. Retinal Degeneration In A Mouse Model Of CLN5 Disease Is Associated With Compromised Autophagy. Sci Rep. 2017 May 9;7(1):1597. doi: 10.1038/s41598-017-01716-1

(12) Miyoshi G, Hjerling-Leffler J, Karayannis T, Sousa VH, Butt SJ, Battiste J, Johnson JE, Machold RP, Fishell G. Genetic fate mapping reveals that the caudal ganglionic eminence produces a large and diverse population of superficial cortical interneurons. J Neurosci. 2010 Feb 3;30(5):1582-94. doi: 10.1523/JNEUROSCI.4515-09.2010.

(13) Xu Q, Guo L, Moore H, Waclaw RR, Campbell K, Anderson SA. Sonic hedgehog signaling confers ventral telencephalic progenitors with distinct cortical interneuron fates. Neuron. 2010 Feb 11;65(3):328-40. doi: 10.1016/j.neuron.2010.01.004.

(14) Okamoto M, Katayama T, Suzuki Y, Hoshino KY, Yamada H, Matsuoka N, Jodo E. Neonatal administration of phencyclidine decreases the number of putative inhibitory interneurons and increases neural excitability to auditory paired clicks in the hippocampal CA3 region of freely moving adult mice. Neuroscience. 2012 Nov 8;224:268-81.

(15) Miller CL, Freedman R. The activity of hippocampal interneurons and pyramidal cells during the response of the hippocampus to repeated auditory stimuli. Neuroscience. 1995 Nov;69(2):371-81.

(16) Gurevicius K, Gureviciene I, Valjakka A, Schachner M, Tanila H. Enhanced cortical and hippocampal neuronal excitability in mice deficient in the extracellular matrix glycoprotein tenascin-R. Mol Cell Neurosci. 2004 Mar;25(3):515-23. 
Barker DJ, Eriksson JG, Forsen T, Osmond C. Fetal origins of adult disease: strength of effects and biological basis. Int J Epidemiol 2002 Dec;31(6):1235-1239.

Barker DJ. The developmental origins of adult disease. J Am Coll Nutr 2004 Dec;23(6 Suppl):588S$595 \mathrm{~S}$

Buka SL, Fan AP. Association of prenatal and perinatal complications with subsequent bipolar disorder and schizophrenia. Schizophr Res. 1999;39:113-119. discussion 160-111. [PubMed] [Google Scholar]

Burek MJ, Oppenheim RW. Cellular Interactions that Regulate Programmed Cell Death in the Developing Vertebrate Nervous System. In: Koliatsos VE, Ratan RR, editors. Cell Death and Diseases of the Nervous System Totowa, NJ: Humana Press; 1999. p. 145-179.

Guilherme Testa-Silva, ${ }^{1}$ Alex Loebel, ${ }^{2}$ Michele Giugliano, ${ }^{3,4,5}$ Christiaan P.J. de Kock, ${ }^{1}$ Huibert D. Mansvelder, ${ }^{1}$ and Rhiannon M. Meredith ${ }^{1}$ Hyperconnectivity and Slow Synapses during Early Development of Medial Prefrontal Cortex in a Mouse Model for Mental Retardation and Autism. Cereb Cortex. 2012 Jun; 22(6): 1333-1342.

Götz M, Stoykova A, Gruss P. Pax6 controls radial glia differentiation in the cerebral cortex. Neuron. 1998 Nov;21(5):1031-44.

Jaaro-Peled H, Hayashi-Takagi A, Seshadri S, Kamiya A, Brandon NJ, Sawa A. Neurodevelopmental mechanisms of schizophrenia: understanding disturbed postnatal brain maturation through neuregulin-1-ErbB4 and DISC1. Trends Neurosci. 2009;32:485-495

Lahiri DK, Maloney B, Zawia NH. The LEARn model: an epigenetic explanation for idiopathic neurobiological diseases. Mol Psychiatry 2009 Nov;14(11):992-1003.

Lahti J, Raikkonen K, Pesonen AK, Heinonen K, Kajantie E, Forsen T, et al. Prenatal growth, postnatal growth and trait anxiety in late adulthood - the Helsinki Birth Cohort Study. Acta Psychiatr Scand 2010 Mar;121(3):227-235.

Marín O, Rubenstein J.L.R. A long, remarkable journey: Tangential migration in the telencephalon.Nature Reviews Neurosciencevolume 2, pages780-790 (2001).

Marques AH, O'Connor TG, Roth C, Susser E, Bjorke-Monsen AL. The influence of maternal prenatal and early childhood nutrition and maternal prenatal stress on offspring immune system development and neurodevelopmental disorders. Front Neurosci 2013 Jul 31;7:120.

McNeil TF. Perinatal risk factors and schizophrenia: selective review and methodological concerns. Epidemiol Rev. 1995;17:107-112.

Minae Niwa et al.Knockdown of DISC1 by in utero gene transfer disturbs postnatal dopaminergic maturation in the frontal cortex and leads to adult behavioral deficits.Neuron. 2010 Feb 25; 65(4): 480-489

Rabinowicz T, de Courten-Myers GM, Petetot JM, Xi G, de los Reyes E. Human cortex development: estimates of neuronal numbers indicate major loss late during gestation. J Neuropathol Exp Neurol 1996 Mar;55(3):320-328. 
Rakic S, Zecevic N. Programmed cell death in the developing human telencephalon. Eur J Neurosci 2000 Aug;12(8):2721-2734.

Roseboom TJ, van der Meulen JH, Ravelli AC, Osmond C, Barker DJ, Bleker OP. Effects of prenatal exposure to the Dutch famine on adult disease in later life: an overview. Mol Cell Endocrinol 2001 Dec 20;185(1-2):93-98. 132

Lahiri DK, Maloney B, Zawia NH. The LEARn model: an epigenetic explanation for idiopathic neurobiological diseases. Mol Psychiatry 2009 Nov;14(11):992-1003. 


1

2

3 23

\section{Loss of $C \ln 5$ leads to altered Gad1 expression and deficits in interneuron development in mice}

Yajuvinder Singh ${ }^{1 \#}$, Henri Leinonen ${ }^{1,2 \#}$, Feroze Fazaludeen ${ }^{1}$, Merja Jaronen ${ }^{1}$, Debbie Guest ${ }^{3}$, 5 Noel Buckley ${ }^{4}$, Nadiya Byts ${ }^{5}$, Petra Oksa ${ }^{1}$, Kari Jalkanen ${ }^{1}$, Imran Iqbal ${ }^{1}$, Mikko Huuskonen ${ }^{1}$,

6 Ekaterina Savchenko ${ }^{1}$, Velta Keksa-Goldsteine ${ }^{1}$, Sweelin Chew ${ }^{1}$, Johanna Myllyharju ${ }^{5}$, Heikki

7 Tanila ${ }^{1}$, Lezanne Ooi ${ }^{6}$, Jari Koistinaho ${ }^{1}$, Katja M. Kanninen ${ }^{1 \S}$, Tarja Malm ${ }^{1 \S *}$.

$9{ }^{1}$ A. I. Virtanen Institute for Molecular Sciences, University of Eastern Finland, Kuopio, Finland

$10{ }^{2}$ Department of Ophthalmology, School of Medicine, University of California Irvine, Irvine, Ca, 11 USA.

$12{ }^{3}$ Animal Health Trust, Lanwades Park, Kentford, Newmarket, Suffolk CB8 7UU, United 13 Kingdom.

$14{ }^{4}$ Department of Psychiatry, University of Oxford, Warneford Hospital, Oxford, OX3 7JX, United 15 Kingdom.

$16{ }^{5}$ Oulu Centre for Cell Matrix Research, Biocenter Oulu and Faculty of Biochemistry and 17 Molecular Medicine, University of Oulu, Oulu, Finland

$18{ }^{6}$ Illawarra Health and Medical Research Institute, School of Biological Sciences, University of 19 Wollongong, Wollongong, NSW, 2522, Australia.

$21 \quad$ \# equal contribution

$22 \S$ equal contribution

24 Address correspondence to:

25 *Tarja Malm

26 A.I.Virtanen Institute for Molecular Sciences

27 University of Eastern Finland

28 Yliopistonranta 1, 70210, Kuopio, Finland.

29 Phone: +358403552209

30 Email: Tarja.malm@uef.fi 


\section{Abstract}

34 The Finnish variant Late Infantile Neuronal Ceroid Lipofuscinosis ( vLINCL $_{\text {Fin }}$ ), also known as 35 CLN5 disease, is caused by mutations in the CLN5 gene. Cln5 is strongly expressed in the 36 developing brain and expression continues into adulthood. CLN5, a protein of unknown function,

37 is implicated in neurodevelopment but detailed investigation is lacking. Using $C \ln 5^{-/}$embryos of 38 various ages and cells harvested from $C \ln 5^{-/}$brains we investigated the hitherto unknown role of $39 \quad \ln 5$ in the developing brain. Loss of $C \ln 5$ results in neuronal differentiation deficits and delays 40 in interneuron development during in utero period. Spesifically, the radial thickness of dorsal 41 telencephalon was significantly decreased in $C \ln 5^{-/}$mouse embryos at embryonic day 14.5 42 (E14.5), and expression of Tuj1, an important neuronal marker during development, was down43 regulated. An interneuron marker calbindin and a mitosis marker $\mathrm{p}-\mathrm{H} 3$ showed down-regulation 44 in ganglionic eminences. Neurite outgrowth was compromised in primary cortical neuronal 45 cultures derived from E16 $\mathrm{Cln}^{-/-}$embryos compared to WT embryos. We show that the 46 developmental deficits of interneurons may be linked to increased levels of the Repressor Element 47 1-Silencing Transcription factor (REST), which we report to bind to Gadl, which encodes 48 glutamate decarboxylase (GAD) 67, a rate-limiting enzyme in the production of GABA. Indeed, 49 adult $C \ln 5^{-/}$mice presented deficits in hippocampal parvalbumin-positive interneurons. 50 Furthermore, adult $\mathrm{Cln} 5^{-/}$mice showed age-independent cortical hyper excitability as measured 51 by electroencephalogram and auditory-evoked potentials. This study highlights the importance of $52 C \ln 5$ in neurodevelopment and suggests that in contrast to earlier reports, CLN5 disease is likely 53 to develop during embryonic stages. 


\section{Introduction}

57 The neuronal ceroid lipofuscinoses (NCLs) constitute a group of inherited lysosomal storage

58 disorders and the most common group of pediatric neurodegenerative disorders (1). Depending on

59 geography and ancestry the incidence of NCLs varies from 1:8000 to 1:100000 $(2,3)$ and is highest

60 in the Nordic countries (4). Most NCLs are inherited in an autosomal recessive manner, but some

61 patients with adult NCL variants show autosomal dominant inheritance (5). Currently, 13

62 genetically distinct human NCLs variants have been identified (6). The childhood forms of NCLs

63 are generally characterized by cognitive and motor deficits, progressive loss of vision, epileptic

64 seizures and premature death (7), while the more rare adult-onset forms are dominated by

65 dementia. Pathological hallmarks of NCLs include progressive neurodegeneration, massive glial

66 activation, and accumulation of auto-fluorescent storage material within lysosomes both in the

67 central nervous system (CNS) and the periphery.

68

69 CLN5 disease, also called Finnish variant Late Infantile Neuronal Ceroid Lipofuscinosis 70 (vLINCL $\left._{\mathrm{Fin}}\right)$, results from mutations in the CLN5 gene. CLN5 disease has an onset at 71 approximately $2-7$ years of age and because no cure exists, culminates in death between 14-36 72 years of age (8). To date, 37 disease causing mutations in the CLN5 gene have been documented 73 (9). Although the exact role of CLN5 remains unknown, it is well accepted that it is a lysosome 74 trafficked soluble glycoprotein $(10,11)$. Similar to other NCL forms, CLN5 deficiency is 75 pathologically characterized by the accumulation of lysosomal auto-fluorescent material in both 76 the CNS and the peripheral tissues $(3,12,13)$.

78 It has been speculated that CLN5 is involved in neurodevelopment. In a pioneering study, 79 Heinonen et al. (14) reported that CLN1 and CLN5 genes are expressed in the embryonic brain 
80 between 37 to 84 days post fertilization, and that the expression of these genes increases during

81 development. The expression of CLN1 and CLN5 is observed in different zones of dorsal

82 telencephalon including the subventricular zone (SVZ), intermediate zone (IZ) and cortical plate

83 (CP), which house the stem cells and migrating and differentiating neuronal populations,

84 respectively. In the mouse brain, $\operatorname{Cln} 5$ is ubiquitously expressed in the entire brain at embryonic

85 day 15 (E15) and peaks at approximately postnatal day 30 (P30) (10). Furthermore, high $C \ln 5$

86 expression is observed in the cerebral cortex, cerebellum and ganglionic eminences (GEs) of the

87 embryonic brain. In contrast, the cerebellar Purkinje cell layer and the hippocampus are the main

88 sites of high $C \ln 5$ expression in the adult mouse brain (10). The diverse spatial and temporal

89 expression of $C \ln 5$ in the different germinative areas of the developing and adult brain suggests

90 that $\operatorname{Cln} 5$ may have a broad role in both embryonic brain development and maintenance of adult

91 brain function. To date, there is no knowledge of the exact role of $C \ln 5$ in neurodevelopment.

92

93 We show here for the first time that loss of $C \ln 5$ triggers alterations in development and defects in

94 embryonic interneurons. This may occur through increased binding of REST to Gadl, which

95 encodes a rate limiting enzyme for GABA in interneurons (15). This study presents evidence that

96 CLN5 functions as a critical modulator of key parameters required for proper neuronal

97 development and maturation, and that the neurodegenerative processes of CLN5 disease

98 pathophysiology have a neurodevelopmental component.

99

100

101 


\section{Results}

\section{Loss of $C \ln 5$ leads to developmental cytoarchitectural changes and perturbations in stem cell} 104 populations in the dorsal telencephalon

105 To investigate neuronal development and cytoarchitecture, brains from $C \ln 5^{-/}$embryos and WT 106 controls at E14.5 were stained with Cresyl Violet. $\sim$ E14.5 is a time point when $C \ln 5$ is ubiquitously 107 expressed in the developing brain and it is the peak of neurogenesis in the mouse embryo. Nissl 108 staining revealed a significant reduction in the radial thickness along the rostro-caudal axis of 109 approximately $31 \%\left(\mathrm{t}_{9}=4.0, P<0.01\right), 27 \%\left(\mathrm{t}_{10}=3.1, P<0.05\right)$ and $28 \%\left(\mathrm{t}_{9}=3.2, P<0.05\right)$ in the $110 C \ln 5^{-/}$embryos along the rostral, intermediate and caudal sections, respectively, when compared 111 to WT mice (Fig. 1A-I).

113 First we investigated whether changes in proliferation, differentiation and/or apoptosis could 114 explain the observed architectural alterations in the E14.5 $C \ln 5^{-/}$embryos. Quantification of Pax6 115 immunoreactivity showed a significant increase of $45 \%\left(t_{9}=2.2, P<0.05\right)$ in the intermediate and $11673 \%(\mathrm{z}=-2.11, P<0.05)$ in the caudal forebrain of the $C \ln 5^{-/}$embryos when compared to their age117 matched WT controls (Fig. 1N).

119 We next examined the differentiation fate of neurons in the wall of the dorsal telencephalon 120 immunohistochemically using Tuj1 as a marker for one of the earliest neuronal populations (16).

121 The Tuj1 immunoreactivity in the CP was significantly reduced in E14.5 Cln5 $5^{-/}$embryos (rostral: $122 \mathrm{z}=2.3, P<0.05$; intermediate: $\mathrm{t}_{10}=2.7, P<0.05$; caudal: $\left.\mathrm{t}_{10}=2.9, P<0.05\right)$ (Fig 1O). On the other hand, 123 the extent of nestin immunoreactivity was not significantly different $(P \geq 0.09)$ between the 124 genotypes in any of the regions analyzed (SI appendix Fig. S1 \& S2). In contrast to E14.5, 
125 alterations in the extent of Tuj1 and Pax6 immunoreactivities were no longer evident at E17.5 in

$126 C \operatorname{Cln} 5^{-/-}$brains (SI appendix Fig. S3) indicating primarily delayed in utero development.

128 Increased apoptosis and altered stem cell proliferation in dorsal telencephalon of E14.5 $C \ln 5^{-}$ 129 /- embryos

130 To investigate whether loss of $C \ln 5$ interferes with the rate of apoptosis, we analyzed the $C \ln 5^{-/}$ 131 and WT embryos by the TUNEL assay (Fig. 2A-B). Indeed, the number of apoptotic cells in the 132 dorsal telencephalon was significantly higher in E14.5 $C \ln 5^{-/}$embryonic brains than in WT 133 controls (Fig. $2 \mathrm{C}, \mathrm{t}_{5}=3.0, P<0.05$ ).

135 We next analyzed if there are any changes in the proliferation rate of the stem cell populations in 136 the dorsal telencephalon by using p-H3 as a marker for mitosis (Fig. 2D-F). Quantification of p$137 \mathrm{H} 3$ immunoreactivity revealed a nearly significant increase in the intermediate (Fig. $2 \mathrm{E}, \mathrm{t}_{9}=2.2$, $138 P=0.06$ ) and a significant increase in the caudal (Fig. $2 \mathrm{~F}, \mathrm{t}_{10}=2.24, P<0.05$ ) parts of the dorsal 139 telencephalon, corresponding to the area where Pax6 immunoreactivity was observed earlier.

141 Loss of $\operatorname{Cln} 5$ affects stem cell proliferation rate and interneuron populations in the ganglionic 142 eminences

143 As a number of previous studies have shown that NCL proteins $(17,18)$ including Cln5 are 144 involved in functioning of interneurons (19) we next assessed whether Cln5 could be implicated 145 in interneuron development during embryonic stages. We stained E14.5 embryonic brain sections 146 against calbindin, a marker for early interneurons, and quantified immunoreactivity at the site of 147 interneuron birth, i.e. at the GEs (Fig 3A-D). Quantification at the principal source of interneurons 
148 during this period, i.e. medial GE (MGE), showed a significant 68\% decrease in immunoreactivity 149 in the $C \ln 5^{-/}$embryos (Fig. 3C, $\mathrm{t}_{8}=3.3, P<0.05$ ). However, the decrease in the calbindin 150 immunoreactivity did not reach a statistical significance level in the lateral GE (LGE; Fig. 3D, $\left.151 \mathrm{t}_{10}=1.9, P=0.09\right)$, Calbindin immunoreactivity in the dorsal telencephalon did not show any 152 alterations in $\mathrm{Cln}^{-/}$embryos (SI appendix Fig. S4).

154 Then, we tested if changes in the proliferation rate of the stem cell populations in the ventral 155 telencephalon could potentially play a role in the interneuronal loss observed in the GEs of $C \ln 5^{-}$ 156 - embryos. Quantification of $\mathrm{p}-\mathrm{H} 3$ positive cells in the GEs revealed a nearly significant reduction 157 in the mitotic cell count in the MGE (Fig. 3I, $\mathrm{z}=1.8, P=0.07$ ) and significant reductions in the LGE 158 (Fig. 3J; $\mathrm{z}=2.5, P<0.01$ ) and caudal GE (CGE; Fig. 3K, $\left.\mathrm{t}_{10}==2.5, P<0.05\right)$ in $C l n 5^{-/}$embryos.

160 We also investigated whether the loss of $C \ln 5$ influences the tangential migration of interneurons 161 from the GEs to the dorsal telencephalon. We analyzed the flux of calbindin immunoreactive cells 162 at the junction of the dorsal telencephalon and ventral telencephalon representing the outflow of 163 interneurons migrating towards various regions of the upper brain from their origin in the GEs. 164 Quantification revealed no differences between genotypes (SI appendix Fig. S5), suggesting that 165 the loss of $C \ln 5$ was unlikely to affect the migration of interneurons towards the dorsal 166 telencephalon. In conclusion, loss of $C \ln 5$ seems to affect interneuron populations of the GEs only.

\section{Reduced number of interneurons in the adult $\operatorname{Cln}^{-/-}$brain}

169 We next investigated whether the observed deficits in the number of developing interneurons 170 during development persist to an adult age. Although loss of interneurons has been reported in 
171 adult $C \ln 5^{-/}$mice (13), we are not aware of any attempt to quantify the loss. We therefore analyzed

172 6-month-old WT and $C \ln 5^{-/}$mouse brains stained with calcium binding protein parvalbumin (PV),

173 one of the well-known markers for the adult brain interneurons. Although we did not detect

174 differences in the numbers of $\mathrm{PV}$ positive interneurons in cortex $\left(\mathrm{t}_{11}=0.6, P=0.5\right.$, data not shown),

175 we found significant reductions in the numbers of PV interneurons in the CA1 (Fig. 4A-C, $\mathrm{t}_{11}=3.7$, $176 P<0.01$ ) and hilar regions (Fig. 4D-F, $\mathrm{t}_{14}=3.0, P<0.01$ ) of adult $C \ln 5^{-/}$hippocampi.

\section{$178 \quad$ Loss of $\boldsymbol{C l n} 5$ suppresses neurite outgrowth}

179 Neurite outgrowth, one of the key aspects of the developmental chain of events in the brain, can

180 be recapitulated under in vitro conditions by primary neural cultures from the developing brain.

181 Thus, we studied the differentiation-related morphological changes in primary cortical neurons 182 derived from $C \ln 5^{-/}$and WT mice by time-lapse microscopy. The live-cell imaging results

183 demonstrate the formation of an extensive neurite network in WT neurons that were accompanied

184 by high neurite length and branching points (Fig. 5A). In contrast, $C \ln 5^{-/}$neurons appeared to 185 exhibit fewer and shorter neurite-like extensions (Fig. 5B). Indeed, neuronal outgrowth was 186 suppressed in $\mathrm{Cln} 5^{-/}$cortical neurons as shown by reduced gain of neurite length as compared to 187 WT neurons (Fig. 5C, $\mathrm{F}_{1.4}=9.0, P<0.05$ ). However, quantified neurite branching analysis showed 188 no difference in the number of branching points between the $C \ln 5^{-/}$and WT cells (data not shown).

190 REST is up-regulated in $\operatorname{Cln}^{-/-}$brains

191 Our previous study showed that $C \ln 5^{-/}$mice exhibit impaired neurogenesis (20). Since the 192 repressor element 1-silencing transcription factor (REST), also called neuron-restrictive silencing 193 factor (NRSF) is a master regulator of neurogenesis, we next evaluated whether REST is 
194 implicated in the observed changes in $C \ln 5^{-/}$mice. Whereas the mRNA levels of REST in the 195 cortical samples of $C \ln 5^{-\curvearrowright}$ E14.5 embryos were unaltered $\left(\mathrm{t}_{13}=0.19, P=0.85\right.$, data not shown), 196 increased REST protein levels were detected in $C \ln 5^{-/}$hippocampi at the age of 6 months (Fig. $\left.1976 \mathrm{~A}, \mathrm{~B}, \mathrm{t}_{11}=2.2, P<0.05\right)$.

199 REST regulates genes involved in the development of GABAergic interneurons

200 To evaluate the genes that REST regulates in neural stem cells, we carried out a ChIP microarray 201 in NS5 cells (Table 1 and SI appendix Table S1). The array revealed that REST regulates genes 202 that are critical for GABAergic development. We thus validated these genes by ChIP-qPCR and 203 confirmed that in neural stem cells REST regulates Gadl and Ptfla, two genes that are important 204 in the development of GABAergic interneurons, along with well-characterised REST target genes, 205 such as Tubb3 (Fig. 6C). Gadl mRNA expression was not altered in total hippocampal samples 206 (data not shown). GAD67 is the enzyme responsible for the conversion of glutamic acid to GABA 207 in interneurons and is controlled by the transcription factor Ptfla $(20,21)$. The NS5 neural stem 208 cells are known to express telencephalic markers and generate GABAergic, GAD67 positive 209 neurons upon differentiation (22). To further evaluate the involvement of REST in regulating these 210 genes, REST function was inhibited by overexpressing dominant negative REST (DN:REST) in 211 NS5 cells. Indeed, Ptfla was silent in control cells and the overexpression of DN:REST induced 212 the expression of Ptfla in NS5 cells, indicating that REST is responsible for silencing this gene in 213 these cells (Fig. 6D). To verify the interaction of REST and Gadl in tissues in vivo, we carried out 214 ChIP-qPCR analysis of hippocampal samples from 5-month-old $\mathrm{Cln}^{-}$- mice and their WT 215 controls. The analysis showed significantly increased binding of REST with Gadl in $\operatorname{Cln} 5^{-/}$mice $216(\mathrm{z}=2.10, P<0.05$, Fig. 6E), consistent with the increased protein expression of REST (Fig. 6A, B). 
217 Table 1. Selected highly enriched genes in ChIP microarray in NS5 cells. Full table showing all 218 genes with > 2-fold mean enrichment is shown in SI appendix Table S1.

\begin{tabular}{|l|l|l|l|}
\hline Gene & Protein/Function & Mean enrichment & STD \\
\hline L1cam & Neural cell adhesion molecule L1 & 44.61 & 63.965 \\
\hline Rnaseh2a & Ribonuclease H2 subunit A & 28.924 & 26.371 \\
\hline Celf4 & Elav-like family member 4, RNA-binding & 27.43 & 21.43 \\
\hline Snap25 & Synaptosomal-associated protein 25 & 20.382 & 15.483 \\
\hline Syt7 & Synaptotagmin-7 & 20.059 & 18.944 \\
\hline Cacna1b & Voltage-dependent Ca2+ channel, N type, a1B subunit & 11.116 & 8.976 \\
\hline Gad1 & Glutamate decarboxylase 1 & 10.372 & 7.974 \\
\hline Meis3 & Homeobox protein Meis3, transcriptional regulator & 9.76 & 6.098 \\
\hline Tubb3 & Tubulin beta-3 chain & 6.184 & 4.972 \\
\hline Ptf1a & Pancreas transcription factor 1 subunit alpha & 2.695 & 2.396 \\
\hline
\end{tabular}

$220 \quad C \ln 5$ deficiency leads to enhanced auditory-evoked potentials

221 To determine whether the observed deficits in the interneuron development have functional 222 consequences in adult mice, we measured auditory evoked potentials (AEPs) and auditory gating 223 that are established methodologies to assess short- and long-latency inhibitory mechanism in vivo 224 and indicative of interneuronal integrity (21-23). The in vivo electrophysiology was performed in 225 awake, head-restrained mice implanted with chronical electrode assembly. The test tone (the 226 second tone of the tone-pair) evoked a clearly suppressed response compared to conditioning tone 227 regardless of mouse genotype or gender (compare Fig. 7 A vs. B and C vs. D). The test 228 tone/conditioning tone amplitude ratio revealed that the response inhibition was decreased in 2229 month-old $\mathrm{Cln}^{-/}$mice compared to their age-matched controls (genders pooled: $\mathrm{F}_{1,35}=3.1$, $230 P=0.09 ; 2$-months: $\left.\mathrm{t}_{35}=2.5, P<0.05\right)($ Fig. $7 \mathrm{~F})$. In other words, the auditory gating was slightly 231 impaired in young adult $C \ln 5^{-/}$mice.

$233 \mathrm{Cln}^{-/-}$male mice show increased electroencephalogram (EEG) power spectral density

234 Brain hyperexcitability may be a consequence of imbalance between brain excitability and 235 inhibition and may be observed in EEG recordings as increased power spectral density (PSD), 236 especially in the gamma band. We performed PSD analysis (i.e. EEG power at different frequency 
237 bands) from EEG signal collected consecutively for $5 \mathrm{~min}$ in still head-fixed $C \ln 5^{-/-}$and WT mice.

238 The PSD was increased in male $C \ln 5^{-/}$mice at all frequency ranges at both 2 months (Fig. 7G;

239 theta: $\mathrm{t}_{11}=3.2, P<0.01$; alpha: $\mathrm{t}_{11}=2.9, P<0.05$; beta: $\mathrm{t}_{11}=4.1, P<0.01$; gamma: $\left.\mathrm{t}_{11}=4.8, P<0.001\right)$

240 and at 6 months of age (Fig $7 \mathrm{H}$; theta: $\mathrm{t}_{10}=2.8, P<0.05$; alpha: $\mathrm{t}_{10}=3.0, P<0.05$; beta: $\mathrm{t}_{10}=4.1$,

$241 P<0.01$; gamma: $\left.\mathrm{t}_{10}=3.8, P<0.01\right)$. In contrast, female $C \ln 5^{-/}$mice displayed similar PSD as their

242 gender-matched controls (Fig. 7I-J). ANOVA for repeated measures revealed no age effect in 243 PSDs between 2 and 6 months of age (WT male: $\mathrm{F}_{1,8}=0.1, P=0.74 ; C \ln 5^{-/}$male: $\mathrm{F}_{1,12}=1.3, P=0.28$;

244 WT female: $\mathrm{F}_{1,12}=0.5, P=0.50 ; C \ln 5^{-/}$female: $\left.\mathrm{F}_{1,14}=0.4, P=0.56\right)$.

245

246 Loss of $\boldsymbol{C l n} 5$ leads to impaired motor coordination and balance

247 Since motor deterioration is a key hallmark of NCLs (7) and hypomyelination has been previously 248 decribed in $C \ln 5^{-/}$mice (24), we were interested in seeing if $C \ln 5^{-/}$mice diplay a motor phenotype 249 and if it is progressive in nature. To this end, we performed a longitudinal motor performance 250 follow-up by Rotarod test (25) from 1 to 10 months of age. Both male and female $C \ln 5^{-/}$mice 251 performed worse than their sex-matched controls in the Rotarod test regardless of age (SI 252 Appendix Fig. 6). We pooled results from male and female mice for statistical analysis due to 253 small group sizes and similar results between the genders. The performance difference between 254 genotypes was significant across all the tested ages and did not aggravate over time $\left(\mathrm{F}_{1,90}=108.8\right.$, $255 P<0.001)$. 


\section{Discussion}

261 Previous studies have shown that NCL associated CLN2, CLN3 and CLN5 genes are active in 262 multipotent neurospheres (26). Moreover, at E14.5, $C \ln 5$ is widely distributed in the developing 263 brain with a high expression in the highly proliferative areas like the ventricular zone (VZ) (10). 264 In the current study, E14.5 $\operatorname{Cn} 5^{-/}$embryos displayed cytoarchitectural deficits in the brain, 265 suggesting that loss of $C \ln 5$ also affects stem cell populations and their differentiation potential. 266 As a further indication of abnormal neuronal development, primary neurons cultured from $\mathrm{Cln} 5^{-/}$ 267 mice showed impaired process formation.

269 Our analysis revealed an increase in the Pax6 positive cells in VZ/SVZ in the caudal brain sections 270 of $C \ln 5^{-/}$mice. An increase in the Pax6 immunoreactivity in $C \ln 5^{-/}$embryos can be due to several 271 reasons such as deficits in radial glial scaffolds, proliferative deficits, apotosis, cell fate choice or 272 a combination of these factors. We did not observe any changes in the radial glial morphology as 273 observed by nestin staining, which is another neural stem/progenitor cell marker. This suggests 274 that radial glial fibers are functionally normal in $C \ln 5^{-/-}$embryos. However, we observed a strong 275 trend towards an increase in the $\mathrm{p}-\mathrm{H} 3$ counts in the dorsal telencephalon in $\mathrm{Cln} 5^{-/}$embryos at 276 E14.5 despite being unable to produce a double staining for Pax6 and p-H3. Nevertheless, our data 277 suggests that Pax6 increase was most likely due to an increase in the proliferative activity of the 278 progenitor cells in the $\operatorname{Cln} 5^{-/}$embryos. Nestin immunoreactivity did not show any expression 279 differences between $C \ln 5^{-/}$and WT emryos in our cohort. In the developing brain virtually all 280 Pax6+ cells are also positive to nestin, as shown by Götz et al. (27). However, the authors also 281 show that there is a significant proportion of cells that are nestin positive but Pax6 negative. Thus, 282 this nestin positive but Pax6 negative but population could overcome the observed difference in 283 the extent of Pax6 positive and nestin positive cell populations observed in our study. 
284 Furthermore, earlier studies have suggested that Pax6 expression has to be "turned off" for proper 285 neuronal differentiation (28). It is plausible that in the absence of $C \ln 5$, the progenitor cells are 286 unable to downregulate Pax6 levels and remain in a "pre-differentiated" state, leading to altered 287 neuronal differentiation. This idea is corroborated by the findings that $C \ln 5^{-/}$mice exhibit a 288 reduced amount of $\beta$-tubulin in the cortex, as well as in primary embryonic cortical neurons (29). 289 Therefore, $C \ln 5$ may be implicated in the maintenance of the microtubular components of the 290 cytoskeleton and in stem cell functioning in the neurogenic compartments of the developing brain. 291 An earlier study found no direct correlation between neuronal loss and timing or distribution of 292 lipofuscin accumulation in $C \ln 5^{-/-}$mice (30), suggesting that the neuronal loss cannot be explained 293 by disease progression upon aging. In support of this, our study now suggest that these alterations 294 may be initiated already during embryonic developmental stages, although we cannot exclude the 295 possibility that loss of $\mathrm{C} \ln 5$ causes a delay rather than a permanent disturbance in the development.

297 Involvement of apoptotic cascades in NCL pathogenesis has been substantiated by TUNEL 298 positive cells in the brains of LINCL and juvenile NCL (JNCL) patients (31), and in a mouse 299 model of infantile NCL (32). CLN5 in conjunction with CLN3 may regulate cellular apoptosis 300 through regulation of lysosomal $\mathrm{pH}$ (33) and dysregulation of sphingolipid metabolism (34), 301 which is also known for CLN2/3/6/8 NCL subtypes (31). We show that the number of TUNEL 302 positive cells is increased in the $C \ln 5^{-/}$embryos at E14.5, suggesting that the apoptosis is 303 excessively activated at an early developmental stage in $C \ln 5^{--}$mice. Therefore, the altered 304 neuronal differentiation observed in or study may result either from an increase in the apoptosis 305 of the differentiating/migrating neurons and/or the inability of the stem cells to undergo normal 
306 differentiation in the absence of $C \ln 5$. Our previous report on altered differentiation of $\operatorname{Cln} 5$

307 deficient NPCs (20) support the latter hypothesis.

308

309 MGE and CGE are the main sources of cortical and hippocampal interneurons $(35,36)$. Here we

310 report that loss of $C \ln 5$ affects the interneuron populations of the developing brain. Loss of 311 calbindin positive interneurons in the E14.5 $C \ln 5^{-/-}$GEs was also accompanied by a reduction in 312 cellular proliferation. Despite the inability of the current study to determine the state of various 313 precursor cell markers in the GEs, it is likely that the loss of calbindin results from a reduced 314 proliferation rate of the resident progenitor populations. GABAergic neurons are affected in NCL 315 disease pathogenesis in various animal models (17) and humans patients (18). Our study provides 316 the first evidence that the loss of interneurons in $C \ln 5^{-/}$mice (13) may indeed be of developmental 317 origin. Since $\mathrm{Cln} 5$ has a high expression in GEs (10), changes in calbindin immunoreactivity might 318 actually signal selective early vulnerability of interneurons and may increase susceptibility to 319 neurodegeneration.

321 We propose that deficits in interneuron development during $\operatorname{Cln} 5$ deficiency arise from increased 322 levels of REST, leading to enhanced binding of REST to Gad1 and Ptfla, thus repressing the 323 production of GABA. Although we do not have direct proof of this in vivo, we suggest a novel 324 model whereby under WT conditions REST expression is down-regulated during GABAergic 325 neuron development, relieving repression of Ptf1a and Gad1. REST, which is increased in Cln5 326 deficiency, is bound to the RE1 sites of Ptfla and Gad1, resulting in their silencing and reduced 327 GABAergic neuronal differentiation. The loss of REST from the RE1 site of Gad1 allows the 328 expression of this gene and subsequent conversion of glutamic acid into GABA. $C \ln 5^{-/}$mice 
329 exhibit significantly increased levels of REST, without evident re-distribution between the nucleus

330 and cytoplasm (data not shown), which possibly impairs neuronal subtype specification, leading

331 to deficits in interneuron numbers. This is consistent with a coherent type 2 feed-forward loop 332 (37). A feed-forward loop such as this would enable a delay in the response of Gad1 to changes 333 in REST levels, which may be of importance in maintaining normal neuronal functions if REST 334 levels are only transiently affected. While our data does not provide direct evidence that REST is 335 controlling the production of GABAergic interneurons in vivo, we demonstrate the direct 336 interaction of REST with Gad1 both in vitro and in vivo, adding further proof for the involvement 337 of REST in interneuron development. Taking into account the loss of interneurons in adult $C \ln 5^{-/-}$ 338 deficient mice, it is plausible that REST is involved in the process of neuronal subtype specification 339 and interneuron differentiation via its control of Gad1. Furthermore, our in vitro ChIP-qPCR data 340 revealed that REST also interacts with TUBB3, which encodes Tuj-1. Thus, an increase in REST 341 may also be responsible for the decrease in Tuj-1 that we observed in $C \ln 5^{-/}$mice. Indeed, REST 342 has been shown to regulate a number of genes associated with GABAergic neurons (38). Taken 343 together, we propose that the loss of the lysosomal protein $C \ln 5$ increases inflammation and 344 oxidative stress, leading to an upregulation of REST and a consequent downregulation of genes 345 required for GABAergic differentiation. Importantly, we show for the first time that this may occur 346 through direct interaction of REST with Gad67.

348 Further evidence for impaired interneuron function comes from electrophysiological recordings in 349 adult $C \ln 5^{-/-}$mice. Impaired auditory gating in female and male $C \ln 5^{-/-}$mice and overall increased 350 power spectral density of the male $C \ln 5^{-/-}$mice all are compatible with decreased inhibition of 351 principal neurons by GABAergic interneurons (21). Impaired auditory gating reflects neural 
352 processing in the so-called extralemniscal pathway rather than the mainstream processing from 353 brainstem auditory nuclei via medial geniculate nucleus to the auditory cortex. The most robust 354 auditory gating is recording in the CA3 field of the hippocampus with local microelectrodes while 355 the gating response via volume conduction can be also seen with parietal screw electrodes (39) as 356 in our study. Thus our finding of reduced auditory gating in $C \ln 5^{-/}$mice is well in agreement with 357 the observed PV+ interneuron loss in area CA3 of hippocampus. At present we do not have an 358 explanation as to why only male $C \ln 5^{-/}$exhibit such a hyperexcited EEG spectra, but females do 359 not. However, males and females have been shown to have estrogen induced differences in 360 hyperexcitability (40). Thus, estrogen could suppress the hyperexcitability in $C \ln 5^{-/}$females. 361 Interestingly, REST has been shown to regulate also a vast number of genes associated with 362 estrogen signaling (38).

364 NCLs have been classically categorized as lysosomal storage diseases with a neurodegenerative 365 component manifesting as progressive neuronal loss and behavioral deficits. Here we provide 366 evidence that already during early embryonic development $\operatorname{Cln} 5^{-/}$mice show alterations in 367 neuronal cytoarchitecture which translates during the postnatal period to a loss of the interneuron 368 populations. It is noteworthy that surrogate markers of interneuron deficits (brain 369 hyperexcitability) in our study do not aggravate over time. Similarly, a major clinical hallmark of 370 NCLs, motor dysfunction, did not aggravate over time as shown by 10-month long Rotarod follow371 up. Although earlier studies have revealed a generalized early myelinization defect in $\mathrm{Cln}^{-/}$mice 372 (24), it is difficult to assess the contribution of hypomyleinization to behavior, since additional 373 pathological changes such as neuroinflammation are usually present in induced hypomyelinization 374 models. It is, however, possible that that the demyelination contributes to the observed impairment 
375 in the Rotarod test that draws on fast communication between the cerebellum and spinal cord via

376 long myelinisated axons. Nevertheless, these data are in line with our previous study showing that

377 impairment in electroretinographic response arising from the eye's retinal pigmented epithelium

378 (RPE) in $\operatorname{Cln}^{-/}$mice do not aggravate upon aging (41). These data suggest that the major 379 neurological symptoms in $C \ln 5^{-/}$mice may be destined from the pre-birth periods.

381 Pathogenic events underlying NCLs may be initiated prenatally $(42,43)$. Our study is the first to 382 show that $\mathrm{Cln} 5$ loss of function leads to significant alterations in the development of embryonic 383 mouse brain. Our findings pose two important questions. Firstly, could malfunction of $C \ln 5$ during 384 early embryonic development set the conditions for disease initiation, which over a period of time 385 escalates to form the pathological basis of the disease? Secondly, could in utero intervention 386 provide a novel window of opportunity for effective therapeutic intervention for the dreaded 387 NCLs.

\section{Materials and methods}

\section{Animals}

391 The $\mathrm{Cln}^{-/}$model was created by gene targeting using insertion of neomycin selectable marker for 392 the disruption of exon 3. The mice were crossbred to C57BL/6J RccHsd background and $393 \mathrm{C} 57 \mathrm{BL} / 6 \mathrm{~J}$ RccHsd mice were used as WT controls (WT). Cln5 $5^{-\nsim}$ mice were a kind gift from Anu 394 Jalanko (13). The embryos were isolated from gravid females at time points E14.5 and E17.5 395 during the gestation period. For $C \ln 5^{-/}$mice and their WT counterparts the day when vaginal plug 396 was detected was designated as E0.5. In addition, adult, 2-10 -month-old adult $C \ln 5^{-/-}$mice and 397 their age matched WT counterparts were included in the study. All experimental procedures were 
398 performed in accordance with the European and Finnish legislations for handling and care of

399 laboratory animals and approved by the Animal Experimental Board in Finland.

400

401 Immunohistochemistry

402 The embryo heads were processes as described by Utriainen et al. (44). Briefly, the embryo heads 403 were dissected in phosphate buffered saline (PBS), fixed in DMSO-methanol at $-20{ }^{\circ} \mathrm{C}$ for one 404 week and then processed in ascending grades of ethanol, cleared in xylene followed by paraffin 405 impregnation and embedding. For immunostains, $4 \mu \mathrm{m}$ thick microtome sections were 406 deparaffined with descending grades of ethanol. The sections were treated with $0.4 \%$ Triton X 100 407 (Sigma-Aldrich, Saint Louis, MA, USA) in PBS for 30 min and blocked using 10\% normal goat 408 serum (NGS) or Mouse IgG (Vector Laboratories, CA, USA). The sections were incubated with 409 primary antibodies in suitable predetermined dilutions overnight, rinsed in PBS-Tween20 and 410 incubated with corresponding Alexa 568 or 488 (Molecular Probes, Invitrogen, Eugene, OR, USA) 411 conjugated secondary antibodies in dark for $2 \mathrm{~h}$ at room temperature. The immunostained sections 412 were mounted in Vectashield (Vector laboratories, Burlingame, CA, USA) containing DAPI. The 413 following primary antibodies were used: PAX-6 (1:400; cat\# AB2237, Millipore, Princeton, MA, 414 USA), Tuj-1 (1:500; cat\# MMS435P, Covance, Burlington, NJ, USA), nestin (1:500; cat\# 415 MAB353, Millipore, Princeton, MA, USA) and phosphohistone-3 (p-H3, Cat\# 06-570, 1:300 416 Millipore, Princeton, MA, USA). Alternatively, the embryo heads were fixed in 4\% 417 parafolmaldehyde (PFA) for $24 \mathrm{~h}$, cryoprotected in $10 \%$ and $20 \%$ sucrose for $24 \mathrm{~h}$ and finally 418 frozen in liquid nitrogen, cut in $20 \mu \mathrm{m}$ thick cryosections and stained as described above. 
420 Calbindin staining was performed using TSA amplification kit (Perkin Elmer, Waltham, MA, 421 USA) according to the manufacturer instructions. Briefly, the deparaffinized sections were treated 422 in $0.3 \% \mathrm{H}_{2} \mathrm{O}_{2}$ in methanol to quench endogenous peroxidase activity, blocked and incubated with 423 primary antibody Calbindin D28K (1:500; cat\# D28K Ab 1778, Millipore, Princeton, MA, USA) 424 overnight. After washing the sections were incubated with biotinylated secondary antibody Vector 425 BA 1000, (1:500, Vector Laboratories, Burlingame, CA, USA) followed by incubation with 426 streptavidin-horseradish peroxidase conjugate. After amplification with fluorophore tyramide 427 (1:300 dilution) the sections were washed, the nuclei stained with Hoechst (Sigma-Aldrich, Louis, $428 \mathrm{MO}, \mathrm{USA}$ ) and slides were mounted in mounting medium (Vecta Laboratories, Burlingame, CA, 429 USA).

431 Immunohistochemical analysis was carried out blinded to the study groups in three anatomically 432 matched sections from the rostrocaudal axis of $\mathrm{Cln}^{-1-}$ and WT embryos. Different layers in the 433 dorsal telencephalon were identified according to Bayer and Altman (45) on the basis of cell 434 morphology and density at 20x magnification. VZ was identified as a cellular region adjacent to 435 ventricles having parallel arrays of cells with elongated nuclei perpendicular to the ventricle. The 436 SVZ consists of disorganized compact layer of cells with rounded nuclei. In the current study, we 437 did not differentiate VZ/SVZ, but pooled them in the analysis of progenitor population zones. The 438 IZ was identified as a cell layer that was less dense than the proliferative VZ/SVZ, with the cells 439 having a tangential orientation. The sub plate (SP) was recognized as a less dense layer below CP 440 with large rounded nuclei. The CP layer had a higher cell density than IZ, with cells having a 441 palisade like arrangement. Mid-dorsal telencephalon of the embryo brain sections was visualized 442 at 10x magnification with Leica AX70 microscope, and immunoreactivity per unit area in the 
443 different layers identified using the above defined criteria was quantified using 200-400 $\mu \mathrm{m}$ wide

444 window with Image Pro Plus 6.0 software. After the analysis, representative images of the E14.5

445 stainings were imported into Photoshop CC 2015 and pseudocolored by converting to gray scale 446 and RGB, and then applying gradient maps with similar parameters to all images. Quantified 447 results were expressed as mean \pm standard deviation $(\mathrm{SD})$.

\section{Cresyl violet staining}

450 The paraffin-processed sections were deparaffinized and stained in $0.1 \%$ cresyl violet acetate 451 (Sigma Aldrich, St. Louis, MO, USA) for $5 \mathrm{~min}$. After rinsing in tap water, the stained sections 452 were differentiated in a solution of $96 \%$ ethanol with a few drops of acetic acid. Thereafter, the 453 sections were dehydrated with ascending grades of $70 \%$ and absolute alcohol, cleared in xylene 454 and finally mounted in DePeX (BDH, UK). The radial thickness of the dorsal telencephalon was 455 quantified from three different locations along the length of the dorsal telencephalon and mean 456 obtained from both sides of the brain. At least three anatomically matching embryonic sections 457 along the rostrocaudal axis were analyzed in both $\mathrm{WT}$ and $\mathrm{Cln} 5^{--}$mice.

\section{$458 \quad$ Parvalbumin staining}

459 Parvalbumin staining was performed on 6-month-old WT and $C \ln 5^{-/}$mouse brain sections by Ni460 DAB (Nickel-Diaminobezidine) method. Briefly the paraformaldehyde (PFA)-fixed $20 \mu \mathrm{m}$ cryo461 sections from adult mice were washed in phosphate buffered saline (PBS). The antigen retrieval 462 was performed by boiling sections in $0.05 \mathrm{M}$ citrate buffer at $84^{\circ} \mathrm{C}$ for $30 \mathrm{~min}$. Next, the blocking 463 of endogenous peroxidase was performed by treating the sections with $0.3 \% \mathrm{H}_{2} \mathrm{O}_{2}$ in methanol for 46430 min followed by washing in PBS with tween (PBST). The sections were treated with anti- 
465 parvalbumin primary antibody (1:750, cat\# 235 Swant, Switzerland) with an overnight incubation 466 in a humidified chamber. The following day the sections were washed with PBST and treated with 467 biotin conjugated secondary antibody (Vector Laboratories, Burlingame, CA, USA) at 1:200 468 dilution followed by treatment with $\mathrm{ABC}$ reagent (Vector Laboratories, Burlingame, CA, USA) 469 for $30 \mathrm{~min}$. For color development, the sections were treated with Ni-DAB solution supplemented 470 with $0.075 \% \mathrm{H}_{2} \mathrm{O}_{2}$. Color development was checked under the microscope and the reaction was 471 stopped by immersion in double-distilled water. All test and control slides were treated similarly.

472 This was followed by dehydration in ascending grades of alcohol, clearing in xylene and mounting 473 in DePeX (BDH, UK).

475 TUNEL assay

476 Terminal deoxynucleotidyl transferase dUTP nick end labeling (TUNEL) staining was performed 477 according to manufacturer instructions (Roche Diagnostics, Mannheim, Germany). Briefly, $20 \mu \mathrm{m}$ 478 thick 4\% PFA fixed E14.5 embryo brain sections were air-dried and rehydrated in PBS. Antigen 479 retrieval was performed in $0.05 \mathrm{M}$ citrate buffer at $80^{\circ} \mathrm{C}$ for $30 \mathrm{~min}$ or in a microwave oven at $480750 \mathrm{~W}$ for $1 \mathrm{~min}$ followed by rapid cooling. TUNEL reaction mixture was added to the test slides 481 followed by incubation in a humidified chamber at $37^{\circ} \mathrm{C}$ for $1 \mathrm{~h}$. The positive control was treated 482 with DNAase I (Sigma Aldrich, St. Loius, MO, USA), and for the negative control slides the 483 enzyme solution was omitted from the treatment. TUNEL positive cells were counted through the 484 entire telencephalic wall from the ventricle to the pial surface from both hemispheres of the 485 embryonic brain, and a mean count obtained from 2-3 anatomically matching sections along the 486 rostrocaudal axis for both WT and $C \ln 5^{--}$mice blinded to the study groups. 
488

489

490

491

492

493

494

495

496

497

498

499

500

501

502

503

504

505

506

507

508

509

510

\section{RNA isolation and semi-quantitative PCR}

REST gene expression was analyzed by semi-quantitative PCR (qPCR) in mouse primary neurons, mouse primary microglia, neuronal progenitor cells, and mouse E14.5 and E17.5 cortical samples. Ptfla gene expression was analyzed for in mouse E14.5 samples, and E17.5 cortical samples and NS5 cells. RNA was isolated from cortical samples dissected from E14.5 embryos using Trizol reagent according to the manufacturer's instructions. The concentration and purity was measured using NanoDrop 100 spectrophotometer (Thermo Fisher Scientific, Waltham, MA, USA). For cDNA synthesis, $500 \mathrm{ng}$ of RNA was reverse transcribed (Thermo Fisher Scientific) according to the manufacturer's instructions. qPCR was performed using AB applied Biosystems StepOnePlus Real-Time PCR System ${ }^{\circledR}$ running StepOne Software® v 2.2.2. In all the experiments, all samples were run in duplicates and normalized to GADPH housekeeping gene control and presented as fold change in the expression using the 2- $\Delta \Delta \mathrm{Ct}$ method where $C t$ is the threshold-cycle value.

\section{Western blotting}

Western blot for REST was performed on E14.5 cortical tissue samples isolated from $C \ln 5^{-/-}$and WT embryos. Equal amounts of protein were loaded onto 10\% SDS-PAGE gels and separated using a Mini-Protean 3 (Bio-Rad) device with $200 \mathrm{~V}$. The separated proteins were transferred onto Hybond-P membrane (GE Healthcare) and blocked using 5\% skimmed milk in PBS with 1\% Tween20. The primary anti-REST antibody (1:1000 dilution, Cat\# NRSF (P-18) sc-15118, Santa Cruz Biotechnology, Dallas, Texas, USA) was incubated overnight at $4{ }^{\circ} \mathrm{C}$, and after secondary HRP-labelled antibody incubation (1:2000 dilution, GE Healthcare) the immunoreactivities were developed using Pierce ECL Plus substrate (Thermo Fischer). Anti- $\beta$-actin was used as a loading control and anti-mouse Cy5 as a secondary antibody (1:1000, Cat\# 715-175-151, Jackson 
511 ImmunoResearch). The immunoreactivities were visualized on Storm 860 Fluoroimages (GE

512 Healthcare) and intensities quantified using ImageQuant software (GE Healthcare).

513

\section{Neurite Outgrowth}

515 The neurite outgrowth dynamics were studied using IncuCyte ZOOM ${ }^{\mathrm{TM}}$ (Essen BioScience, Ann 516 Arbor, MI, USA) live content imaging platform. Briefly, primary cortical neuronal cultures 517 derived from E16 $C \ln 5^{-/-}$and WT embryos were prepared as described by Byts et al. (46). Cells

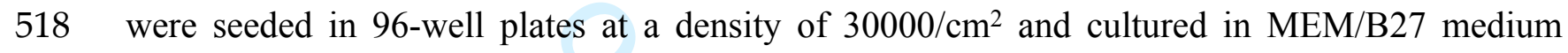
519 (Invitrogen, Carlsbad, CA, USA) supplemented with sodium bicarbonate, sodium pyruvate, L520 glutamine, penicillin, streptomycin and $0.6 \%$ glucose. Cultures were incubated at $37^{\circ} \mathrm{C}$ under $5 \%$ $521 \mathrm{CO}_{2} / 95 \%$ air and $90 \%$ humidity without medium exchange up to six days. Images were taken each $52224 \mathrm{~h}$ by IncuCyte ZOOM ${ }^{\mathrm{TM}}$. Finally, images were analyzed by Neuro Track ${ }^{\mathrm{TM}}$ software (Essen 523 BioScience, Ann Arbor, MI, USA) to produce data on neurite dynamics during an extended period 524 of growth. In each experiment, $\sim 3000$ neurons from 36 non-overlapping images from twelve wells 525 were analyzed per condition.

526

527 Tangential migration analysis

528 Interneurons migrate from the GEs of the ventral telencephalon towards the dorsal telencephalon, 529 by tangential migration. This interneuron migration was assessed by placing a window measuring 530 about $200 \mu \mathrm{m}$ in width spanning the entire telencephalic wall at the confluence of dorsal 531 telencephalon and ventral telencephalon. Calbindin immunoreactive cells in this window that 
532 represented the migrating interneurons were quantified in both WT and $C \ln 5^{-/}$embryos with Image

533 Pro-Plus or Image $\mathrm{J}$ to estimate the flux of cellular migration as described earlier (47).

534

\section{$535 \quad$ NS5 cell culture and treatment}

536 The mouse neural stem cell line NS5 cells were a kind gift from Prof. Austin Smith, University of 537 Edinburgh, UK and cultured as described (22) in NS-A media (Euroclone S.p.A, Pero, Italy) with $53810 \mathrm{ng} / \mathrm{ml} \mathrm{bFGF}, 10 \mathrm{ng} / \mathrm{ml}$ EGF (both Peprotech, London, UK), $50.25 \mu \mathrm{g} / \mathrm{ml}$ pathocyte, $100 \mu \mathrm{g} / \mathrm{ml}$ 539 apotransferrin, $16 \mu \mathrm{g} / \mathrm{ml}$ putrescine dihydrochloride, $25 \mu \mathrm{g} / \mathrm{ml}$ insulin, $19.8 \mathrm{ng} / \mathrm{ml}$ progesterone, $540 \quad 0.03 \mu \mathrm{M}$ sodium selenite, $1.9 \mathrm{mM}$ L-glutamine (all from Sigma). Cells were infected with an 541 adenovirus expressing green fluorescent protein (GFP) or an adenovirus expressing GFP and the 542 DNA-binding domain of REST (DN:REST) for $48 \mathrm{~h}$ at which point cells were approximately $80 \%$ 543 confluent and $70 \%$ expressing the adenovirus as judged by GFP fluorescence. NS5 were infected 544 with recombinant adenoviruses: (Ad-) control empty adenovirus, or (Ad DN:REST) dominant545 negative construct (36). Purified adenovirus was added to subconfluent cells at the minimum titer, 546 such that $>90 \%$ of cells became GFP-fluorescent with minimal cell death. RNA was harvested 48

$547 \mathrm{~h}$ post-infection. The efficacy of DN:REST overexpression in depressing target gene expression 548 and of siRNAs in knocking down REST mRNA has been validated by Bibel et al. (48).

\section{Identification of REST target genes in NS5 cells by microarray analysis}

551 We utilised a database of RE1 elements in the mouse genome to create a microarray consisting of 552574 RE1 elements found across the mouse genome and allow genome wide identification of REST 553 occupancy in NS5 NSCs. In addition, features representing 40 control regions not in the vicinity 554 of an RE1 element were included and used as the background. Input DNA and ChIP DNA were 
555 labelled with two different cyanine dyes (Cy3 and Cy5) and used to interrogate the array. The 556 ratio of ChIP DNA: input DNA could then be calculated and normalised to the ratio for the control 557 regions. The control regions were not occupied by REST and showed a 1:1 ratio ChIP DNA: input 558 DNA. Similarly, putative RE1s that showed a 1:1 ratio were deemed unoccupied by REST. Of 559 the RE1 sites on the array, RE1 elements associated with 151 genes were found to have an 560 enrichment ratio above the input of 2 fold or more, from an average of three biological repeats 561 (independent experiments). The control regions used on the array were found to provide a range 562 of signal intensities in the input channel with an average of $1.24 \pm 0.18$. Data are shown in SI 563 appendix Table S1 for all RE1 bindings sites showing enrichment $>2$-fold.

\section{Reverse transcription PCR}

566 Reverse transcription (RT) PCR was performed as described previously by Ooi et al. (49). Briefly, 567 the cells were harvested in $1 \mathrm{ml}$ Tri-reagent (Sigma), RNA-purified as per the manufacturer's 568 instructions, and resuspended in $50 \mu \mathrm{l}$ of Tris-EDTA, pH 8.0. Genomic DNA was removed by 569 incubation with $1 \mu \mathrm{l}$ of DNase ( 2 units) and $5 \mu \mathrm{l}$ of $10 \times$ buffer (Ambion) for $30 \mathrm{~min}$ at $37^{\circ} \mathrm{C} .5 \mu \mathrm{g}$ 570 of RNA was made up to $50 \mu \mathrm{l}$ with Milli-Q water and was reverse-transcribed with $2.5 \mu \mathrm{l}$ of 571 random primers $(1.25 \mu \mathrm{g})$ and $2.5 \mu \mathrm{l}$ of oligo(dT) $(1.25 \mu \mathrm{g}), 20 \mu \mathrm{l}$ of $5 \times$ buffer, $20 \mu \mathrm{l}$ of $8 \mathrm{mM}$ $572 \mathrm{dNTPs}, 2.5 \mu \mathrm{l}$ of RNasin (100 units), and $2.5 \mu \mathrm{l}$ of Moloney murine leukemia virus $\mathrm{H}(-)$ reverse 573 transcriptase (500 units) at $37{ }^{\circ} \mathrm{C}$ for $60 \mathrm{~min}$. cDNA samples were purified using a PCR 574 purification kit (Qiagen), and of the resulting $100 \mu \mathrm{cDNA}, 2 \mu \mathrm{l}$ was used in a $20-\mu 1$ real-time 575 PCR reaction in duplicates in a Bio-Rad iCycler MyiQ. Non-reverse-transcribed RNA samples 576 were included in the PCR to control for genomic DNA contamination. 
578 The Ptfla gene expression primer sequences were:

579

580 Sense - CTTGCAGGGCACTCTCTTTC

581 Anti-sense - AGTTTTCTGGGGTCCTCTGG

582

\section{Chromatin Immunoprecipitation}

584 The chromatin immunoprecipitation was carried out as described by Ooi et al. (49). Briefly, after 585 washing the cells with PBS, the cells were cross-linked with $1 \%$ formaldehyde for $10 \mathrm{~min}$ at room 586 temperature. After quenching with glycine, the cells were harvested and the chromatin was 587 fragmented into $\sim 500$-bp lengths by sonication. The chromatin was precleared with $5 \%$ bovine 588 serum albumin-blocked protein G-Sepharose and incubated with primary antibodies or control 589 IgG. After incubating the chromatin-antibody complexes with protein G-Sepharose beads, the 590 chromatin-antibody-bead complexes were collected by centrifugation, washed and eluted with $1 \%$ 591 SDS in $100 \mathrm{mM} \mathrm{NaHCO}$. The samples were de-cross-linked by incubation at $65^{\circ} \mathrm{C}$ for $6 \mathrm{~h}$, and 592 treated with $0.5 \mu \mathrm{l}$ of $10 \mathrm{mg} / \mathrm{ml}$ RNase and $9 \mu 1$ of $25 \mathrm{mg} / \mathrm{ml}$ proteinase $\mathrm{K}$. Thereafter the DNA 593 was purified by phenol-chloroform extraction and resuspended in $100 \mu 1$ water. Anti-REST 594 antibody (Cat\# NRSF (H-290) sc-25398X) from Santa Cruz Biotechnology was used. PCR primers 595 were designed proximal to RE1s, and qPCR was performed in duplicates. The fold enrichment 596 was calculated by dividing the starting quantities of DNA in the immunoprecipitated samples by 597 that of the control antibody (IgG for affinity-purified antibodies or normal rabbit serum for crude 598 sera antibody preparations).

599

600 The Ptfla RE1 primers were: 
601

602

603

604 The Gadl RE1 primers were:

605 Sense - GCTCAGCGGGATATTGAAAA

606 Antisense - CTTTGACGCAAAACTCGATG

608 For the tissue samples chromatin immunoprecipitation was performed as previously by 609 Mascanfroni et al. (50) with few modifications. Briefly, hippocampal tissue samples from 5 610 months old mice were dissected out and homogenized over ice in PBS with Ultra-Turrax 611 homogenizer (Daigger Scientific Inc, Vernon Hills, IL, USA), cross-linked with 1\% 612 paraformaldehyde and quenched with glycine after which the samples were washed twice with 613 PBS and lysed with cell lysis buffer $(50 \mathrm{mM}$ Tris- $\mathrm{HCl}, \mathrm{pH} 7.6,1 \mathrm{mM} \mathrm{CaCl}, 0.2 \%$ Triton, $5 \mathrm{mM}$ 614 sodium butyrate and $50 \mu \mathrm{g} / \mathrm{ml}$ PMSF) over ice for $15 \mathrm{~min}$. The chromatin pellet was collected with 615 centrifugation and lysed with ChIP lysis buffer (10 mM Tris-HCl, pH 7.6, $10 \mathrm{mM}$ EDTA, $0.1 \%$ 616 SDS, $10 \mathrm{mM}$ Sodium butyrate and $50 \mu \mathrm{g} / \mathrm{ml}$ PMSF) and sonicated to shear the chromatin. $10 \mu \mathrm{g}$ 617 of antibody was prebound for $6 \mathrm{~h}$ to protein A- and protein G-Dynal magnetic beads (Invitrogen, 618 USA), washed three times with ice-cold PBS plus 1\% BSA, added to the chromatin diluted with 619 ChIP incubation buffer (1\% Triton X-100, 2 mM EDTA, 150 mM NaCl, 20 mM Tris-HCl, pH 8.0) 620 and immunoprecipitated, with rotation, overnight. The magnetic bead-chromatin complexes were 621 then washed three times with RIPA buffer (50 mM HEPES (pH 7.6), $1 \mathrm{mM}$ EDTA, $0.7 \% \mathrm{Na}$ 622 deoxycholate, $1 \% \mathrm{NP}-40,0.5 \mathrm{M} \mathrm{LiCl}$ ) followed by two times with TE buffer. Immunoprecipitated 623 chromatin was then extracted with $1 \% \mathrm{SDS}, 0.1 \mathrm{M} \mathrm{NaHCO} 3$ and heated at $65^{\circ} \mathrm{C}$ for $8 \mathrm{~h}$ to reverse 
624 the paraformaldehyde cross-linking. DNA fragments were purified with a GeneJet Gel Extraction

625 Kit (ThermoFisher Scientific, USA) and analyzed using the Taqman Fast Universal PCR Master

626 Mix (\#4367846, Life Technologies) and gad1 (Mm04207432_g1).

627

628 EEG and power spectral density analysis

629 Two-month-old mice were implanted with an electrode assembly (WT male, $\mathrm{n}=6 ; \operatorname{Cln}^{-/-}$male, $630 \mathrm{n}=7$, WT female, $\mathrm{n}=7, C \ln 5^{-/}$female, $\mathrm{n}=8$ ) under isoflurane anesthesia (induction: $4-4.5 \%$, flow $631400-450 \mathrm{ml} / \mathrm{min}$; maintenance: $2-2.5 \%$, flow $200-220 \mathrm{ml} / \mathrm{min}$ ). Briefly, the animal was secured 632 into a stereotaxic frame (Kopf Instruments, Tujunga, CA, USA). A subcutaneous injection of 633 lidocaine $(0.3 \mathrm{ml}$, Lidocain $10 \mathrm{mg} / \mathrm{ml}$, Orion, Espoo, Finland) was given under the scalp. 634 Thereafter the scalp was opened with an incision and the skull was cleaned. Screw holes 635 (electrodes and anchors) were drilled with a dental drill leaving the dura mater intact. The active 636 electrodes were positioned bilaterally above the parietal cortex (anterior/posterior, AL: - $0.8 \mathrm{~mm}$; 637 medial/lateral, ML: $\pm 1.5 \mathrm{~mm}$ from bregma), and two screws on the frontal bone (AP: $1.5 \mathrm{~mm}$; 638 ML: $\pm 1.5 \mathrm{~mm}$ ) served as the reference and ground electrodes. Three anchor screws were attached 639 to the occipital and frontal bones. The screws were connected to a miniconnector (Mill-Max, 640 Mouser Electronics, Mansfield, TX, USA) with insulated copper wire (diameter $200 \mu \mathrm{m}$ ), and the 641 whole construct was covered with dental acrylic cement. An i.p. injection of carprofen at $5 \mathrm{mg} / \mathrm{kg}$ 642 was given to provide post-surgical analgesia (Rimadyl Vet $50 \mathrm{mg} / \mathrm{ml}$, Zoetis, Helsinki, Finland).

643 The animals were let to recover for 4 days after the surgery without handling. Thereafter, they 644 were adapted to head-restraint for 3 consecutive days in 20-min daily sessions. 
646 The EEG signal from the parietal screw was referred to a frontal screw and recorded in calm head-

647 fixed mice for $5 \mathrm{~min}$. The signal was amplified (1000 x) with an AC amplifier (A-M Systems Inc.,

648 Sequim, WA, USA), bandpass-filtered between 1-1000 Hz and digitized at $2 \mathrm{kHz}$. The data were 649 acquired by SciWorks 7.2 program (DataWave Technologies, Loveland, CO, USA). The power 650 spectral density (PSD) was estimated using Welch's method of spectral estimation using MatLab 651 (MatLab R2011, MathWorks, Natick, MA, USA). PSD was inspected between 4-46 Hz in $1 \mathrm{~Hz}$ 652 bins. The bins were grouped as frequency bands of 4-10 Hz (theta), 11-16 Hz (alpha), 17-30 Hz 653 (beta) and 31-46 Hz (gamma), and the PSDs at each bin within these frequency bands were 654 averaged for analysis. The EEG was recorded at 2 months and at 6 months of age. All recordings 655 were carried out blinded to the study groups.

656

657 Auditory-evoked potentials

658 Auditory-evoked potentials (AEPs) were recorded after acquisition of EEG signal for the PSD 659 analysis using the auditory gating paradigm. Mice remained head-fixed and the AEPs were evoked 660 using a pair of click tones (conditioning and test tones, $500 \mathrm{~ms}$ between a pair of clicks, inter661 stimulus interval $10 \mathrm{~s}$; both tones: $3 \mathrm{kHz}$, duration $10 \mathrm{~ms}, 70 \mathrm{~dB}$ ). A total of 30 click-pairs were 662 delivered and responses were averaged for analysis. In the offline analysis, a baseline was 663 determined as the average amplitude at -100 to $0 \mathrm{~ms}$ from the stimulus onset, for each AEP 664 response. The first major negative deflection at around $40 \mathrm{~ms}$ from the stimulus onset was defined 665 as N1, and its amplitude was measured from the baseline to the peak. Only the N1 component was 666 included in the statistical analysis due to high variability in late occurring AEP components. 667 Recordings that did not present typical AEP waveform (i.e. major negative deflection at $\sim 40 \mathrm{~ms}$ 668 and positive 100-200 ms from stimulus onset) were removed from analysis. Paired-pulse inhibition 
669 was assessed by dividing test tone amplitude by conditioning tone amplitude. All recordings were

670 carried out blinded to the study groups.

671

672 Rotarod

673 Mice were tested with the accelerating Rota-Rod ${ }^{\circledR}$ apparatus (Ugo Basile, Comerio, Italy) for

674 motor coordination and balance. The day before the test, the mice were accustomed to stay on

675 constantly rotating $(4 \mathrm{rpm})$ round rod $(2 \mathrm{~cm}$ in diameter $)$ in two consecutive 2 -min sessions. On

676 the test day, mice were first allowed to walk on the rod at constant speed ( $4 \mathrm{rpm})$ for $1 \mathrm{~min}$. Then

677 the timing was started and rod rotation accelerated from $4 \mathrm{rpm}$ to $40 \mathrm{rpm}$ steadily within $5 \mathrm{~min}$.

678 The time to fall off the rod (or turn three full rounds around with the rod) was recorded until a 6-

679 min cut-off time. All mice were tested three times with a break of approximately one hour between

680 trials. The mean fall-off time across the three trials was used in the analysis. Group sized in rotarod

681 are indicated in Supplementary Information (SI) appendix Table S2. Rotarod was carried out 682 blinded to the study groups.

683

684 Statistical analysis

685 Statistical analysis was performed using GraphPad Prism 7 software (LaJolla, CA, USA). 686 Student's T-test or nonparametric Mann-Whitney U-test were used to compare the 687 immunohistochemical quantification results between $C \ln 5^{-/}$and WT samples (two-tailed tests). 688 The electrophysiology and rotarod data analyses were performed using analysis of variance 689 (ANOVA). Genotype-effects (between-subject factor), age-effects (within-subjects factor) and 690 genotype-age interactions were tested. The ANOVAs were followed by Bonferroni's post-hoc 691 tests. Results are displayed as mean \pm SD and statistical significance was set at $\mathrm{p}<0.05$. 
692

\section{Acknowledgements}

694 This study was supported by the Academy of Finland. H.L. was supported by Doctoral Program 695 of Molecular Medicine at the University of Eastern Finland, and by Predoctoral Research Grants 696 from Eye and Tissue Bank Foundation (Finland), The Finnish Cultural Foundation and Kuopio 697 University Foundation, and by Postdoctoral Research Grants from Fight for Sight (USA), Eye and 698 Tissue Bank Foundation, The Osk. Huttunen Foundation, The Finnish Cultural Foundation and 699 Orion Research Foundation. We thank Ms. Mirka Tikkanen, Stefano Doccini and Filippo 700 Santorelli for technical assistance.

701

702 Conflict of Interest Statement:

703 The authors have no conflict of interest to declare.

704

705

706

707

708

709

710

711

712 


\section{References}

7141 Haltia, M. (2006) The neuronal ceroid-lipofuscinoses: from past to present. Biochim. 715 Biophys. Acta, 1762, 850-856.

7162 Rider, J.A. and Rider, D.L. (1988) Batten disease: past, present, and future. Am. J. Med. 717 Genet. Suppl., 5, 21-26.

7183 Santavuori, P. (1988) Neuronal ceroid-lipofuscinoses in childhood. Brain Dev., 10, 80-83.

7194 Goebel, H.H. (1996) The neuronal ceroid-lipofuscinoses. Semin. Pediatr. Neurol., 3, 270720278.

7215 Josephson, S.A., Schmidt, R.E., Millsap, P., McManus, D.Q. and Morris, J.C. (2001)

722 Autosomal dominant Kufs' disease: a cause of early onset dementia. J. Neurol. Sci., 188, 51-60.

7236 Williams, R.E. and Mole, S.E. (2012) New nomenclature and classification scheme for the 724 neuronal ceroid lipofuscinoses. Neurology, 79, 183-191.

7257 Wisniewski, K.E., Kida, E., Connell, F. and Zhong, N. (2000) Neuronal ceroid 726 lipofuscinoses: research update. Neurol. Sci., 21, S49-56.

7278 Uvebrant, P. and Hagberg, B. (1997) Neuronal ceroid lipofuscinoses in Scandinavia. 728 Epidemiology and clinical pictures. Neuropediatrics, 28, 6-8.

7299 NCL Resource (2019). University College London, June 3th 2019, available at:

730 https://www.ucl.ac.uk/ncl-disease/mutation-and-patient-database/mutation-and-

731 patient-datasheets-human-ncl-genes

73210 Holmberg, V., Jalanko, A., Isosomppi, J., Fabritius, A.L., Peltonen, L. and Kopra, O. 733 (2004) The mouse ortholog of the neuronal ceroid lipofuscinosis CLN5 gene encodes a soluble 734 lysosomal glycoprotein expressed in the developing brain. Neurobiol. Dis., 16, 29-40. 
73511 Isosomppi, J., Vesa, J., Jalanko, A. and Peltonen, L. (2002) Lysosomal localization of the 736 neuronal ceroid lipofuscinosis CLN5 protein. Hum. Mol. Genet., 11, 885-891.

73712 Tyynela, J., Suopanki, J., Santavuori, P., Baumann, M. and Haltia, M. (1997) Variant late 738 infantile neuronal ceroid-lipofuscinosis: pathology and biochemistry. J. Neuropathol. Exp. 739 Neurol., 56, 369-375.

74013 Kopra, O., Vesa, J., von Schantz, C., Manninen, T., Minye, H., Fabritius, A.L., Rapola, J., 741 van Diggelen, O.P., Saarela, J., Jalanko, A. et al. (2004) A mouse model for Finnish variant late 742 infantile neuronal ceroid lipofuscinosis, CLN5, reveals neuropathology associated with early 743 aging. Hum. Mol. Genet., 13, 2893-2906.

74414 Heinonen, O., Kyttala, A., Lehmus, E., Paunio, T., Peltonen, L. and Jalanko, A. (2000)

745 Expression of palmitoyl protein thioesterase in neurons. Mol. Genet. Metab., 69, 123-129.

74615 Asada, H., Kawamura, Y., Maruyama, K., Kume, H., Ding, R.G., Kanbara, N., Kuzume, 747 H., Sanbo, M., Yagi, T. and Obata, K. (1997) Cleft palate and decreased brain gamma748 aminobutyric acid in mice lacking the $67-\mathrm{kDa}$ isoform of glutamic acid decarboxylase. Proc. Natl. 749 Acad. Sci. U S A, 94, 6496-6499.

75016 Lee, M.K., Tuttle, J.B., Rebhun, L.I., Cleveland, D.W. and Frankfurter, A. (1990) The 751 expression and posttranslational modification of a neuron-specific beta-tubulin isotype during 752 chick embryogenesis. Cell Motil. Cytoskeleton, 17, 118-132.

75317 March, P.A., Wurzelmann, S. and Walkley, S.U. (1995) Morphological alterations in 754 neocortical and cerebellar GABAergic neurons in a canine model of juvenile Batten disease. Am. 755 J. Med. Genet., 57, 204-212.

75618 Braak, H. and Goebel, H.H. (1978) Loss of pigment-laden stellate cells: a severe alteration 757 of the isocortex in juvenile neuronal ceroid-lipofuscinosis. Acta Neuropathol., 42, 53-57. 
75819 Cooper, J.D., Messer, A., Feng, A.K., Chua-Couzens, J. and Mobley, W.C. (1999)

759 Apparent loss and hypertrophy of interneurons in a mouse model of neuronal ceroid lipofuscinosis:

760 evidence for partial response to insulin-like growth factor-1 treatment. J. Neurosci., 19, 25567612567.

76220 Savchenko, E., Singh, Y., Konttinen, H., Lejavova, K., Mediavilla Santos, L., Grubman, 763 A., Karkkainen, V., Keksa-Goldsteine, V., Naumenko, N., Tavi, P. et al. (2017) Loss of Cln5 764 causes altered neurogenesis in a mouse model of a childhood neurodegenerative disorder. Dis. 765 Model Mech., 10, 1089-1100.

76621 Gurevicius, K., Gureviciene, I., Valjakka, A., Schachner, M. and Tanila, H. (2004)

767 Enhanced cortical and hippocampal neuronal excitability in mice deficient in the extracellular 768 matrix glycoprotein tenascin-R. Mol. Cell. Neurosci., 25, 515-523.

76922 Ethridge, L.E., White, S.P., Mosconi, M.W., Wang, J., Byerly, M.J. and Sweeney, J.A. 770 (2016) Reduced habituation of auditory evoked potentials indicate cortical hyper-excitability in 771 Fragile X Syndrome. Transl. Psychiatry., 6, e787.

77223 Hershman, K.M., Freedman, R. and Bickford, P.C. (1995) GABAB antagonists diminish 773 the inhibitory gating of auditory response in the rat hippocampus. Neurosci. Lett., 190, 133-136.

77424 Schmiedt, M.L., Blom, T., Blom, T., Kopra, O., Wong, A., von Schantz-Fant, C., Ikonen,

775 E., Kuronen, M., Jauhiainen, M., Cooper, J.D. et al. (2012) Cln5-deficiency in mice leads to 776 microglial activation, defective myelination and changes in lipid metabolism. Neurobiol. Dis., 46, $777 \quad 19-29$.

77825 Jones, B.J. and Roberts, D.J. (1968) A rotarod suitable for quantitative measurements of 779 motor incoordination in naive mice. Naunyn Schmiedebergs Arch. Exp. Pathol. Pharmakol., 259, 780211. 
78126 Fabritius, A.L., Vesa, J., Minye, H.M., Nakano, I., Kornblum, H. and Peltonen, L. (2014)

782 Neuronal ceroid lipofuscinosis genes, CLN2, CLN3 and CLN5 are spatially and temporally co-

783 expressed in a developing mouse brain. Exp. Mol. Pathol., 97, 484-491.

78427 Gotz, M., Stoykova, A. and Gruss, P. (1998) Pax6 controls radial glia differentiation in the 785 cerebral cortex. Neuron, 21, 1031-1044.

78628 Bel-Vialar, S., Medevielle, F. and Pituello, F. (2007) The on/off of Pax6 controls the tempo 787 of neuronal differentiation in the developing spinal cord. Dev. Biol., 305, 659-673.

78829 von Schantz, C., Saharinen, J., Kopra, O., Cooper, J.D., Gentile, M., Hovatta, I., Peltonen, 789 L. and Jalanko, A. (2008) Brain gene expression profiles of $C \ln 1$ and $C \ln 5$ deficient mice unravels 790 common molecular pathways underlying neuronal degeneration in NCL diseases. BMC Genomics, $7919,146$.

79230 von Schantz, C., Kielar, C., Hansen, S.N., Pontikis, C.C., Alexander, N.A., Kopra, O., 793 Jalanko, A. and Cooper, J.D. (2009) Progressive thalamocortical neuron loss in Cln5 deficient 794 mice: Distinct effects in Finnish variant late infantile NCL. Neurobiol. Dis., 34, 308-319.

79531 Lane, S.C., Jolly, R.D., Schmechel, D.E., Alroy, J. and Boustany, R.M. (1996) Apoptosis 796 as the mechanism of neurodegeneration in Batten's disease. J. Neurochem., 67, 677-683.

79732 Gupta, P., Soyombo, A.A., Atashband, A., Wisniewski, K.E., Shelton, J.M., Richardson, 798 J.A., Hammer, R.E. and Hofmann, S.L. (2001) Disruption of PPT1 or PPT2 causes neuronal ceroid 799 lipofuscinosis in knockout mice. Proc. Natl. Acad. Sci. U S A, 98, 13566-13571.

80033 Holopainen, J.M., Saarikoski, J., Kinnunen, P.K. and Jarvela, I. (2001) Elevated lysosomal $801 \mathrm{pH}$ in neuronal ceroid lipofuscinoses (NCLs). Eur. J. Biochem., 268, 5851-5856. 
80234 Haddad, S.E., Khoury, M., Daoud, M., Kantar, R., Harati, H., Mousallem, T., Alzate, O.,

803 Meyer, B. and Boustany, R.M. (2012) CLN5 and CLN8 protein association with ceramide

804 synthase: biochemical and proteomic approaches. Electrophoresis, 33, 3798-3809.

80535 Xu, Q., Cobos, I., De La Cruz, E., Rubenstein, J.L. and Anderson, S.A. (2004) Origins of 806 cortical interneuron subtypes. J. Neurosci., 24, 2612-2622.

80736 Tricoire, L., Pelkey, K.A., Erkkila, B.E., Jeffries, B.W., Yuan, X. and McBain, C.J. (2011)

808 A blueprint for the spatiotemporal origins of mouse hippocampal interneuron diversity. $J$. 809 Neurosci., 31, 10948-10970.

81037 Mangan, S. and Alon, U. (2003) Structure and function of the feed-forward loop network 811 motif. Proc. Natl. Acad. Sci. U S A, 100, 11980-11985.

81238 Abrajano, J.J., Qureshi, I.A., Gokhan, S., Zheng, D., Bergman, A. and Mehler, M.F. (2009)

813 REST and CoREST modulate neuronal subtype specification, maturation and maintenance. PLoS 814 One, 4, e7936.

81539 Moxon, K.A., Gerhardt, G.A., Bickford, P.C., Austin, K., Rose, G.M., Woodward, D.J. 816 and Adler, L.E. (1999) Multiple single units and population responses during inhibitory gating of 817 hippocampal auditory response in freely-moving rats. Brain Res., 825, 75-85.

81840 Swaab, D.F., Chung, W.C., Kruijver, F.P., Hofman, M.A. and Hestiantoro, A. (2003) Sex 819 differences in the hypothalamus in the different stages of human life. Neurobiol. Aging, 24 Suppl 820 1, S1-16; discussion S17-19.

82141 Leinonen, H., Keksa-Goldsteine, V., Ragauskas, S., Kohlmann, P., Singh, Y., Savchenko, 822 E., Puranen, J., Malm, T., Kalesnykas, G., Koistinaho, J. et al. (2017) Retinal Degeneration In A 823 Mouse Model Of CLN5 Disease Is Associated With Compromised Autophagy. Sci. Rep., 7, 1597. 
82442 Oswald, M.J., Palmer, D.N., Kay, G.W., Shemilt, S.J., Rezaie, P. and Cooper, J.D. (2005)

825 Glial activation spreads from specific cerebral foci and precedes neurodegeneration in 826 presymptomatic ovine neuronal ceroid lipofuscinosis (CLN6). Neurobiol. Dis., 20, 49-63.

82743 Kay, G.W., Palmer, D.N., Rezaie, P. and Cooper, J.D. (2006) Activation of non-neuronal 828 cells within the prenatal developing brain of sheep with neuronal ceroid lipofuscinosis. Brain 829 Pathol., 16, 110-116.

83044 Utriainen, A., Sormunen, R., Kettunen, M., Carvalhaes, L.S., Sajanti, E., Eklund, L., 831 Kauppinen, R., Kitten, G.T. and Pihlajaniemi, T. (2004) Structurally altered basement membranes 832 and hydrocephalus in a type XVIII collagen deficient mouse line. Hum. Mol. Genet., 13, 20898332099.

83445 Bayer, S.A. and Altman, J. (1991) Neocortical development. Raven Press, New York.

83546 Byts, N., Samoylenko, A., Fasshauer, T., Ivanisevic, M., Hennighausen, L., Ehrenreich, H. 836 and Siren, A.L. (2008) Essential role for Stat5 in the neurotrophic but not in the neuroprotective 837 effect of erythropoietin. Cell Death Differ., 15, 783-792.

83847 Pozas, E. and Ibanez, C.F. (2005) GDNF and GFRalpha1 promote differentiation and 839 tangential migration of cortical GABAergic neurons. Neuron, 45, 701-713.

84048 Bibel, M., Richter, J., Schrenk, K., Tucker, K.L., Staiger, V., Korte, M., Goetz, M. and 841 Barde, Y.A. (2004) Differentiation of mouse embryonic stem cells into a defined neuronal lineage. 842 Nat. Neurosci., 7, 1003-1009.

84349 Ooi, L., Belyaev, N.D., Miyake, K., Wood, I.C. and Buckley, N.J. (2006) BRG1 chromatin 844 remodeling activity is required for efficient chromatin binding by repressor element 1 -silencing 845 transcription factor (REST) and facilitates REST-mediated repression. J. Biol. Chem., 281, 3897484638980. 
84750 Mascanfroni, I.D., Takenaka, M.C., Yeste, A., Patel, B., Wu, Y., Kenison, J.E., Siddiqui,

848 S., Basso, A.S., Otterbein, L.E., Pardoll, D.M. et al. (2015) Metabolic control of type 1 regulatory

849 T cell differentiation by AHR and HIF1-alpha. Nat. Med., 21, 638-646.

850

851

852

853

854

855

856

857

858

859

860

861 


\section{Figure legends}

863 Figure 1. Cytoarchitectural changes at E14.5 in Chn $^{-/-}$embryos. Nissl stained sections from

864 E14.5 WT (A, B, C) and $C \ln 5^{-/}$embryos (D, E, F) show a significant reduction in the radial 865 thickness of the dorsal telencephalon (DT) wall along the rostral (G) intermediate (H) and caudal 866 (I) sections. Scale bar in A-F $=100 \mu \mathrm{m}$, magnification $4 \mathrm{X}, \mathrm{n}=6$ for $\mathrm{WT}, \mathrm{n}=5$ for $C \ln 5^{-/},{ }^{*} P<0.05$, $867 * * P<0.01$ with Student's T-test, data expressed as mean $\pm \mathrm{SD}$. The red horizontal bars in the 868 pictures indicate radial thickness of the pallial wall. Representative images of Pax6 and Tuj1 869 immunoreactivity from WT $(\mathbf{J}, \mathbf{L})$ and $C \ln 5^{-/}(\mathbf{K}, \mathbf{M})$ embryonic DT. Scale bar $100 \mu \mathrm{m}$, 870 magnification 10X. The histograms in $\mathbf{N}$ and $\mathbf{O}$ show results from Pax6 and Tuj1 quantification 871 from DT along the rostral caudal axis (rostral, intermediate and caudal dorsal telencephalon, 872 respectively. ${ }^{*} P<0.05,{ }^{* *} P<0.01$ with Student's T-test, data expressed as mean $\pm \mathrm{SD}, \mathrm{n}=6$ or 7 for 873 WT, $\mathrm{n}=5-6$ for $C \ln 5^{-/}$.

874

875

876

877

878

879

880

881

882

883

55

56 
884 Figure 2. Loss of Cln5 leads to increased apoptosis and proliferative deficits in the dorsal 885 telencephalon (DT) at E14.5. The TUNEL positive cells were visualized in the developing E14.5

886 (A) WT and (B) $C \ln 5^{-/-}$brains. Scale bar $50 \mu \mathrm{m}$, magnification $10 \mathrm{X}$. The graph in $\mathbf{C}$ represents the 887 quantification of TUNEL staining that was performed across the entire DT wall from the ventricles 888 to the border of the pia, presented as average count from 2-3 sections along the rostral-caudal axis. $889 * P<0.05$ in Student's T-test, data expressed as mean $\pm \mathrm{SD}, \mathrm{n}=4$ for $\mathrm{WT}, \mathrm{n}=3$ for $C \ln 5^{-/}$. The rate 890 of proliferation in WT and $C \ln 5^{-/}$DT was examined by counting of p-H3 positive cells in rostral 891 (D), intermediate (E) and caudal (F) DT. ${ }^{*} P<0.05$, with Student's T-test, data expressed as 892 mean $\pm \mathrm{SD}, \mathrm{n}=5-7$ for both genotypes. $\mathrm{CP}=$ cortical plate, $\mathrm{IZ}=$ intermediate zone, $\mathrm{SVZ}=$ 893 subventricular zone, $\mathrm{VZ}=$ ventricular zone.

894

895

896

897

898

899

900

901

902

903

904

905

906 


\section{Figure 3. Loss of $\operatorname{Cln} 5$ affects interneuron populations and stem cell proliferation rate in the}

908 gangiolic eminences (GEs). Calbindin, a marker for early interneurons, was assessed by

909 immunostaining in the MGE in WT (A) and $C \ln 5^{-/-}$embryos $(\mathbf{B})$. Scale bar $=100 \mu \mathrm{m}$, magnification

910 10X. The graphs in C-D show the quantification results of the calbindin immunoreactivity in MGE

911 and LGE. $* P<0.05$ in Student's T-test, data expressed as mean $\pm \mathrm{SD}$, $\mathrm{n}=6-7$ for $\mathrm{WT}, \mathrm{n}=4-5$ for

$912 C \ln 5^{-}$. The rate of proliferation in WT and $C \ln 5^{-/}$mice's GEs was examined by counting of $\mathrm{p}-\mathrm{H} 3$

913 positive cells. Representative images show p-H3 staining in the MGE and LGE (E-H). E14.5 Cln5-

914 - embryos have a lower number of proliferating cells in the LGE and CGE in comparison to the

915 WT embryos (J-K). Scale bar: $100 \mu \mathrm{m}$, magnification: 10X. ${ }^{*} P<0.05, P<0.01 * *$ with Student's T-

916 test, data expressed as mean $\pm \mathrm{SD} . \mathrm{MGE}=$ medial ganglionic eminence, $\mathrm{LGE}=$ lateral ganglionic

917 eminence, $\mathrm{CGE}=$ caudal ganglionic eminence.

918

919

920

921

922

923

924

925

926

927

928 
929 Figure 4. Adult Cln5-/ mice exhibit alterations in Parvalbumin (PV) positive interneurons.

930 Representative images from the hippocampi of 6-month-old WT (A) and $C \ln 5^{--}$(E) mice show a 931 reduced number of PV stained interneurons in the CA1 layer in $C \ln 5^{-/-}$mice. Images a1 and b1 932 show an enlarged view of the area of the quantification in WT and $C \ln 5^{-/}$mice, respectively, and 933 the graph $\mathbf{C}$ shows the quantification result. $\mathrm{n}=6$ for WT, $\mathrm{n}=7$ for $C \ln 5^{-}$. The black arrows in $\mathbf{A}$ 934 and $\mathbf{B}$ point to the boundary of $200 \mu \mathrm{m}$ distance where the quantification was performed. Images 935 D and $\mathbf{E}$ show hilar PV interneurons from 6-month-old WT and $C \ln 5^{-/}$animals respectively. 936 Quantification of the hilar region (F) revealed a significantly lower number of PV-positive 937 interneurons in $C \ln 5^{-/}$mice compared to their WT controls. $\mathrm{n}=9$ for WT, $\mathrm{n}=7$ for $C \ln 5^{-/}$. The area 938 surrounded by white dashed lines in $\mathbf{D}$ and $\mathbf{E}$ show the hilar region quantified for analysis while 939 the white arrowheads point to the PV immunoreactive cells. The data was obtained from male and 940 female mice. Scale bar for D-G is $50 \mu \mathrm{m}$, magnification: $10 \mathrm{X},{ }^{* *} P<0.01$, data expressed as mean $941 \pm$ SD.

942

943

944

945

946

947

948

949

950 
951 Figure 5. Loss of Cln5 impairs neurite outgrowth. Representative images of neurite outgrowth in 952 WT (A) and $C \ln 5^{-/}$(B) cortical neurons. Scale bar: $80 \mu \mathrm{m}$, magnification: 10X. Dashed rectangles 953 in A and B represent areas in magnified panels. Quantification of neurite length $(\mathbf{C})$ was performed 954 from two different embryos per genotype with more than 300 neurons analyzed per embryo. 955 Quantification showed that the loss of $C \ln 5$ decreases neurite length. $* P<0.05$ with one-way 956 ANOVA, data expressed as mean \pm SEM.

957

958

959

960

961

962

963

964

965

966

967

968

969

970

971

972

973 
974 Figure 6. REST levels are increased in adult Cln5 $5^{-/-}$hippocampi and REST regulates genes

975 involved in GABAergic neuron differentiation. Representative image of the levels of REST

976 protein in WT and $C \ln 5^{-/}$mouse hippocampi as assessed by Western blotting (A). Quantification

977 of REST levels as normalized to $\beta$-actin revealed a significant increase in the levels of REST

978 protein in $C \ln 5^{-/}$brains (B). $\mathrm{n}=6-7, * P<0.05$, data expressed as mean $\pm \mathrm{SD}$. ChIP identified

979 REST occupancy at known and novel RE1 sites. REST targets included genes involved in

980 GABAergic neuron differentiation, including Ptfla and Gadl in NS5 cells (C). Ptfla expression

981 is silenced by REST and inhibition of REST function de-represses Ptfla expression. Ptfla was

982 silent in control adenovirus infected cells (control) and induced following infection of NS5 cells

983 with dominant negative REST (DN:REST) (D). Expression is shown normalized to cyclophilin

$984\left(\times 10^{-5}\right)$. Data is shown as mean of three individual experiments each with minimum of three

985 technical replicates. (E) Chip-qPCR assay from hippocampal samples of 5-month-old $C \ln 5^{-/}$mice

986 show increased interaction of REST with Gadl.

987

988

989

990

991

992

993

994

995

996 
997 Figure 7. Cortical hyperexcitability in adult Cln5 $^{-/-}$mice. Auditory-evoked potentials (AEP) and 998 power spectral density (PSD) analysis from EEG signal was used to investigate cortical 999 hyperexcitability in vivo. The AEPs and EEG were collected in head-fixed awake mice (see 1000 Material \& Methods for details). A-D: Group-averaged waveforms at 2 month of age for condition $1001(\mathbf{A}, \mathbf{C})$ and test $(\mathbf{B}, \mathbf{D})$ tones. (WT male, $\mathrm{n}=3 ; C \ln 5^{-/}$male, $\mathrm{n}=5$; WT female, $\mathrm{n}=6$; $C \ln 5^{-/}$female, $1002 \mathrm{n}=5$ ). The condition and test tone (both tones: $3 \mathrm{kHz}, 70 \mathrm{~dB}$ ) was separated by $500 \mathrm{~ms}$, and the 1003 tone-pair was delivered in $10 \mathrm{~s}$ intervals for 30 times. E: Condition tone amplitudes at 2 and 6 1004 months of age. F: Test tone - condition tone ratio reveals impaired paired-pulse inhibition in $\mathrm{Cln} 5^{-/}$ 1005 mice as compared to WT mice at 2-months of age (genders pooled, genotype effect: $F_{1,35}=3.1$, $1006 P=0.09$; interaction: $\left.\mathrm{F}_{1,35}=3.2, P=0.08\right)$. G-J: PSDs at 2 and 6 months of age. PSDs were analyzed 1007 from continuous (5 min) EEG recording (WT male, $\mathrm{n}=5(-6)$; $C \ln 5^{-/-}$male, $\mathrm{n}=7$; WT female, $\mathrm{n}=7$; $1008 C \ln 5^{-/}$female, $\mathrm{n}=8$ ). PSDs at $1 \mathrm{~Hz}$ intervals were acquired and averaged for statistical analysis at 1009 theta $(4-10 \mathrm{~Hz})$, alpha $(11-16 \mathrm{~Hz})$, beta $(17-30 \mathrm{~Hz})$ and gamma $(31-46 \mathrm{~Hz})$ frequencies. Note the 1010 pronounced increase in PSD in male $C \ln 5^{-}$mice but not in females, similarly as in response to 1011 condition tone in AEP experiment (A vs. C). Statistical analysis was performed by 2-way ANOVA 1012 followed by Bonferroni posthoc test: $* P<0.05$, ${ }^{*} P<0.01$. Data are presented as means \pm SD. 1013 1014 1015 1016 1017 1018 1019 
1020 Abbreviations:

1021 AEP, auditory evoked potential; CGE, caudal ganglionic eminences; CP, cortical plate; CNS, 1022 central nervous system; DT, dorsal telencephalon; EEG, electroencephalography; GEs, ganglionic 1023 eminences; IZ, intermediate zone; LGE, lateral ganglionic eminences; MGE, medial ganglionic 1024 eminences; NCL, neuronal ceroid lipofuscinosis; PSD, power spectral density; PV, parvalbumin; 1025 REST, repressor element 1-silencing transcription factor; SB, sub plate; SD, standard deviation; 1026 SVZ, subventricular zone; VZ, ventricular zone; WT, wild-type. 

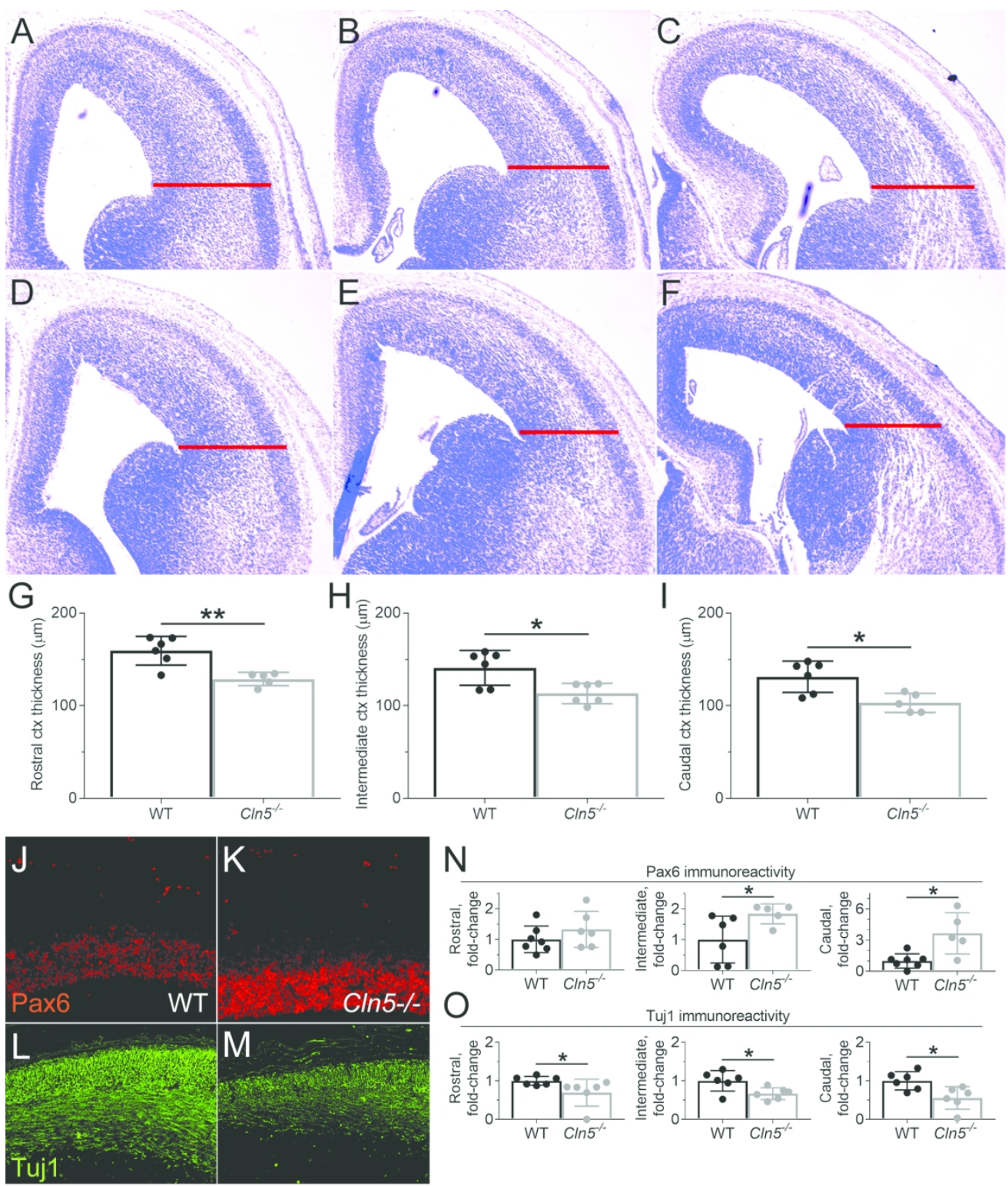

Figure 1. Cytoarchitectural changes at E14.5 in Cln5-/- embryos. 

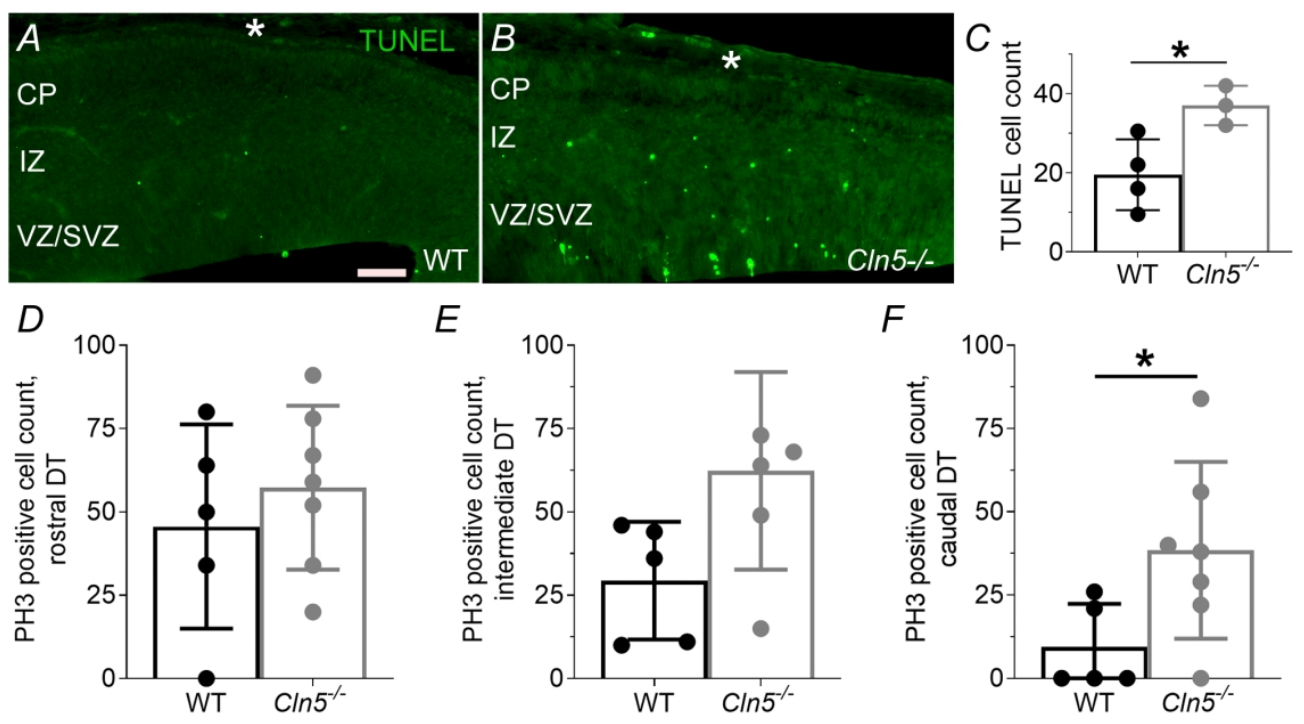

Figure 2. Loss of $\mathrm{Cln} 5$ leads to increased apoptosis and proliferative deficits in the dorsal telencephalon (DT) at E14.5. 
Calbindin immunoreactivity
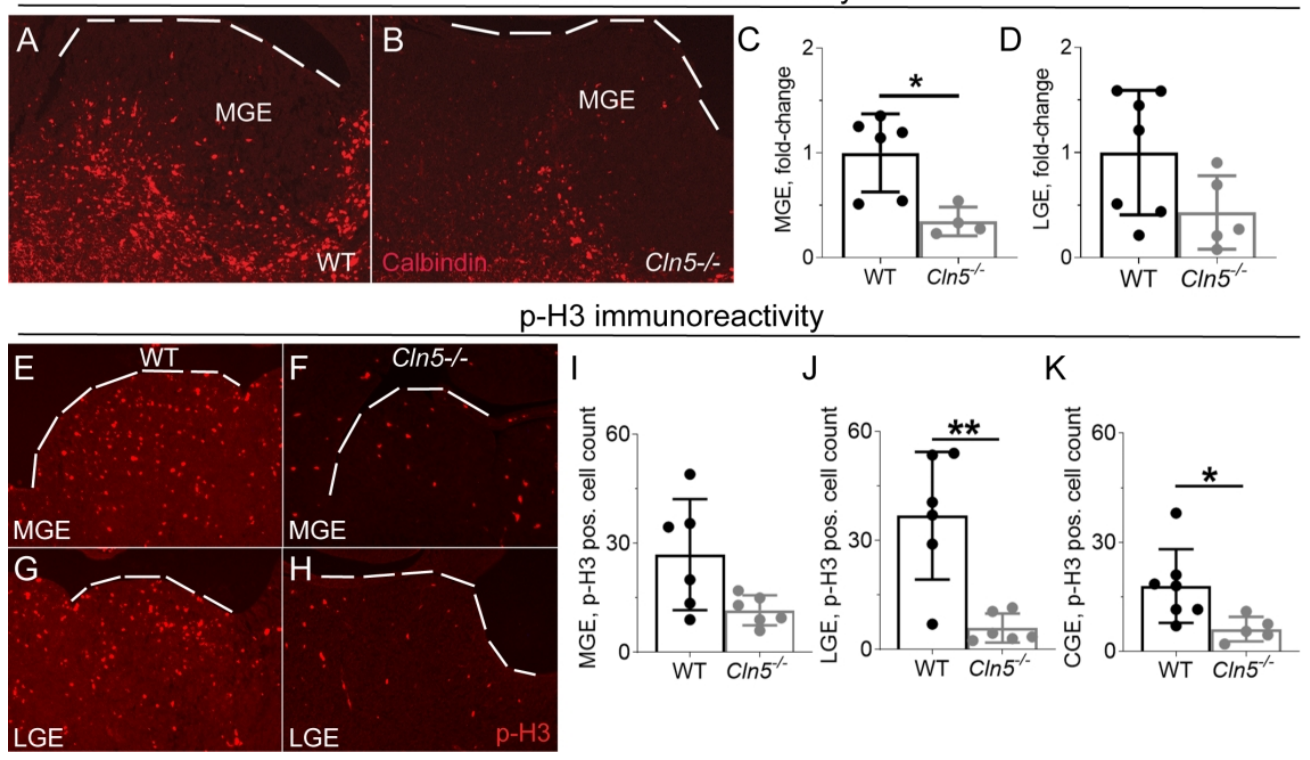

Figure 3. Loss of $\operatorname{Cn} 5$ affects interneuron populations and stem cell proliferation rate in the gangiolic eminences (GEs). 

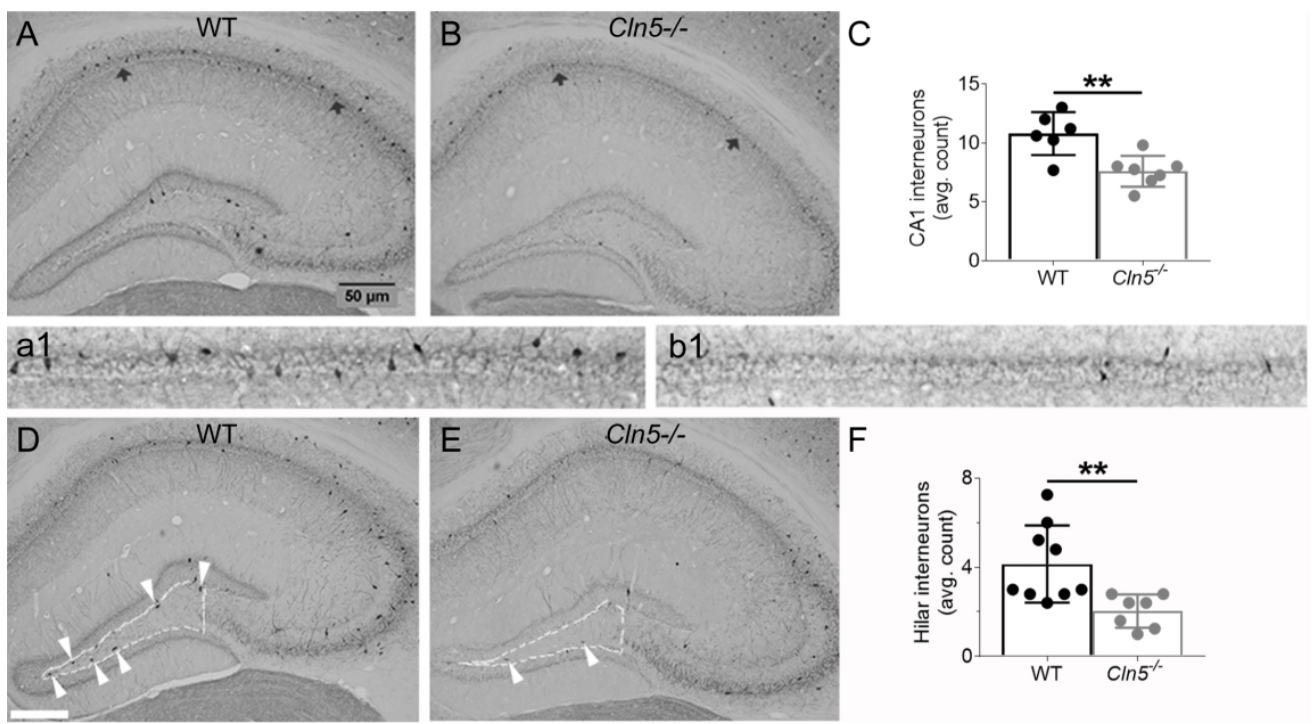

Figure 4. Adult Cln5-/- mice exhibit alterations in Parvalbumin (PV) positive interneurons. 

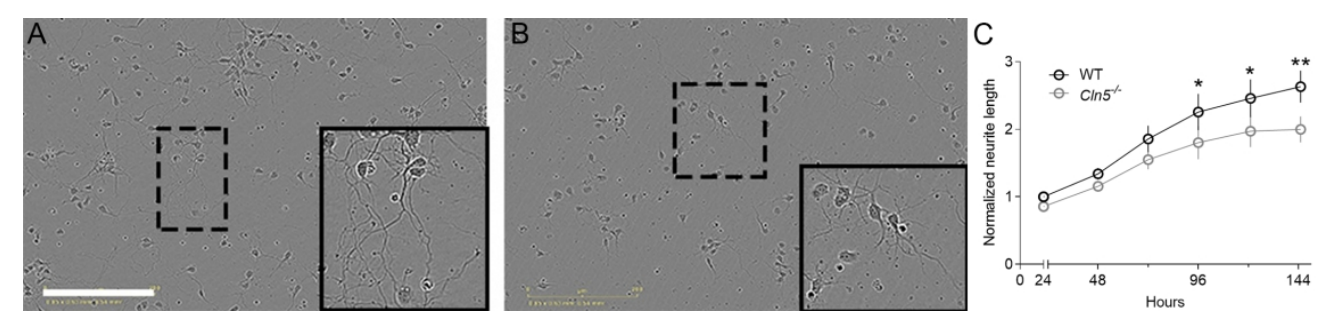

Figure 5. Loss of Cln5 impairs neurite outgrowth.

$188 \times 42 \mathrm{~mm}(300 \times 300 \mathrm{DPI})$ 


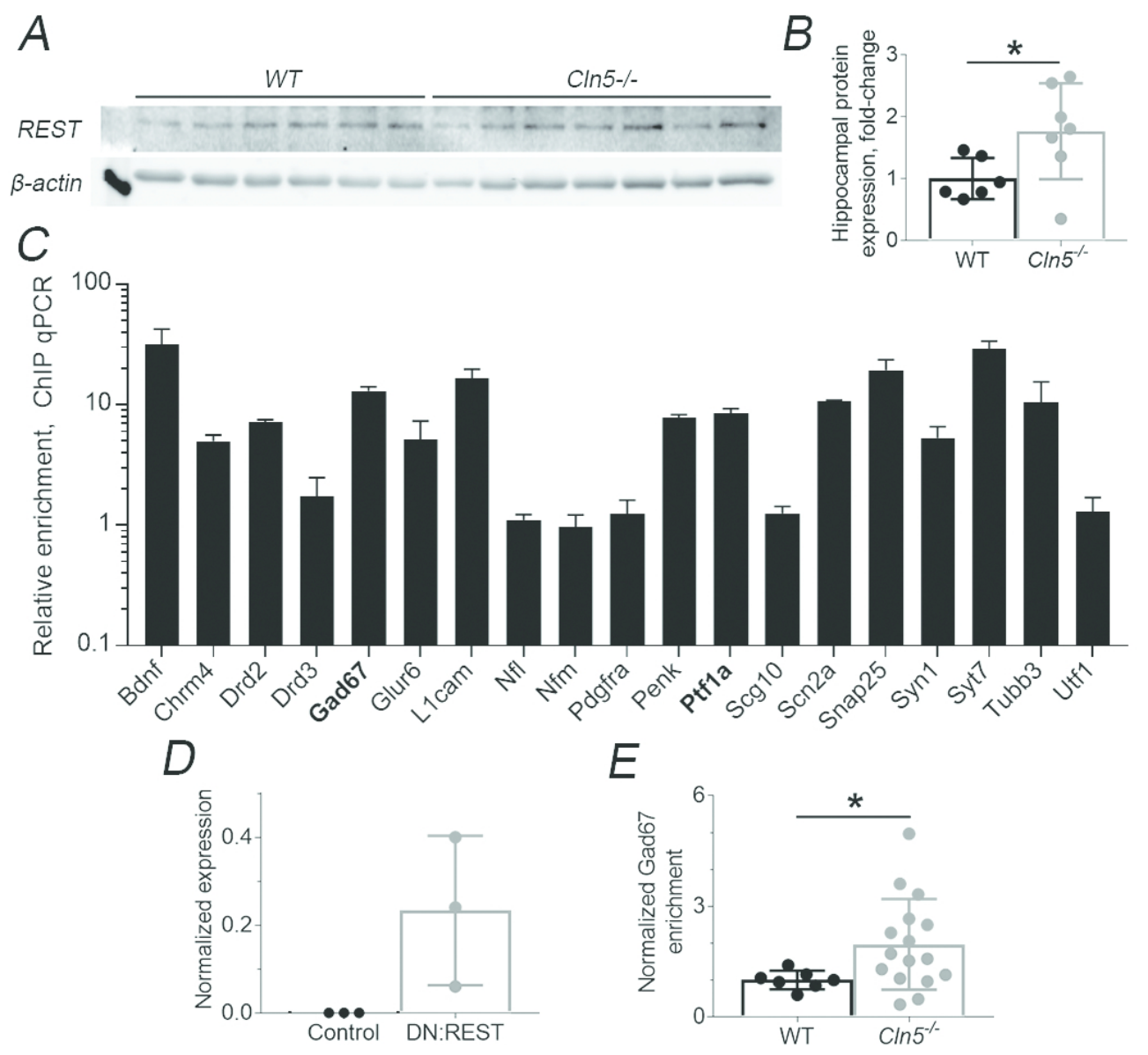

Figure 6. REST levels are increased in adult CIn5-/- hippocampi and REST regulates genes involved in GABAergic neuron differentiation. 


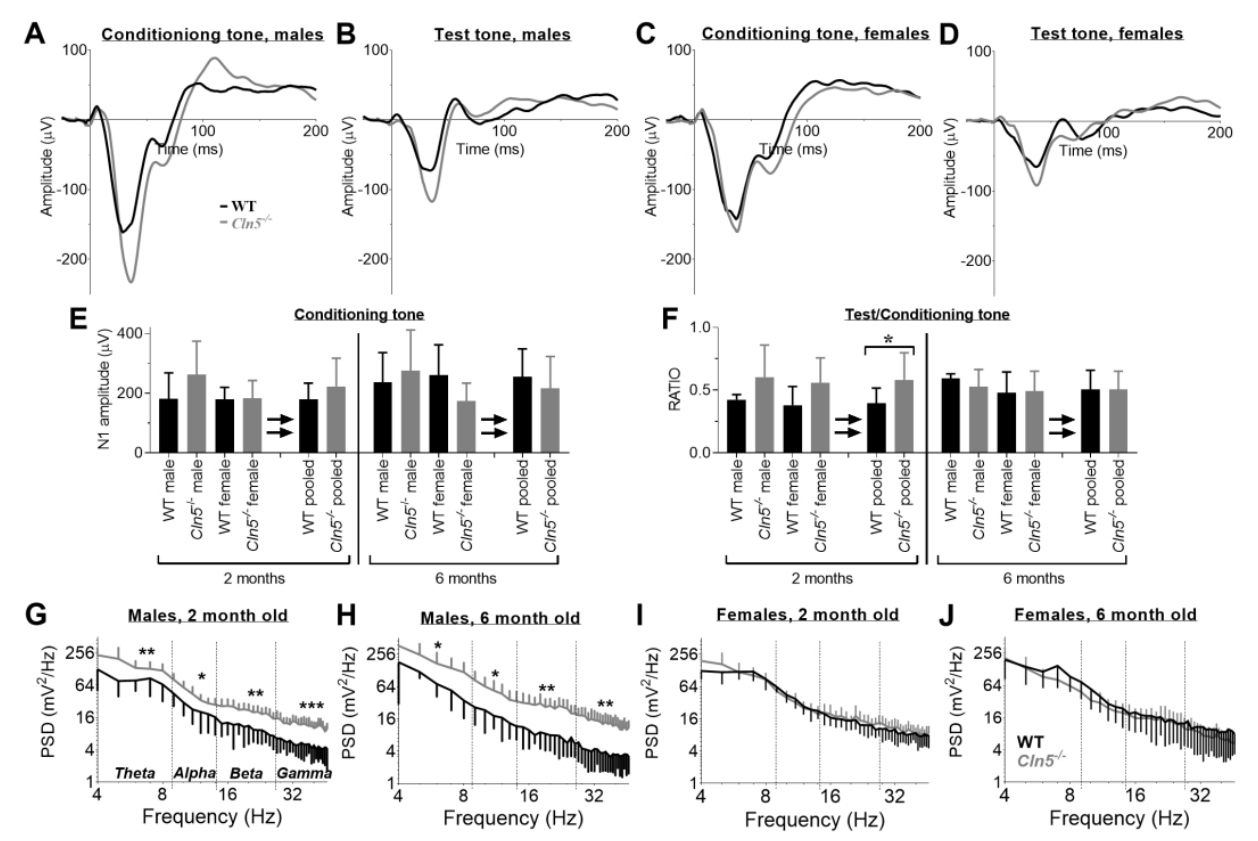

Figure 7. Cortical hyperexcitability in adult Cln5-/- mice.

$200 \times 131 \mathrm{~mm}(300 \times 300 \mathrm{DPI})$ 